\title{
O ENFOQUE DE ANÁLISE DE POLÍTICAS E A POLÍTICA PÚBLICA DO PÓLO E PARQUE DE ALTA TECNOLOGIA DE CAMPINAS ${ }^{1}$
}

\author{
Rogério Bezerra da Silva
}

\author{
Renato Dagnino
}

\begin{abstract}
RESUMO
O artigo analisa a politica pública do Pólo e Parque de Alta Tecnologia de Campinas (PATC) que, como uma das orientações da politica científica e tecnológica brasileira, vem sendo elaboradas nas três últimas décadas. Para isso, utiliza o Enfoque de Análise de Políticas (EAn), que não exige apenas a comparação entre os objetivos da política e os resultados logrados com sua implementação. Ele busca explicar as falhas na consecução dos objetivos a partir do exame do seu momento de formulação. Isto é, do processo decisório e dos projetos políticos e dos modelos cognitivos dos atores com ela envolvidos. A análise realizada aponta que após três décadas do início dessa Política Pública os seus resultados têm sido bastante modestos. A explicação disso pode estar no fato dela ter sido uma emulação de experiências similares ocorridas em paises de capitalismo avançado por iniciativa de integrantes da comunidade de pesquisa nacional.
\end{abstract}

PALAVRAS-CHAVE: enfoque de análise de políticas; políticas públicas; pólo e parque de alta tecnologia.

\section{INTRODUÇÃO}

O artigo, por meio do Enfoque de Análise de Políticas (EAn), analisa a política pública do Pólo e Parque de Alta Tecnologia de Campinas (PATC), que começou a ser elaborada no final dos anos 1970 e que é considerada por muitos como bemsucedida.

Essa análise está orientada a responder a duas perguntas: i) a política pública do PATC conseguiu alcançar os objetivos e metas estipuladas? ii) Por que a política apresenta tais resultados? Isso porque o viés metodológico do EAn conduz o analista de políticas a verificar não somente se suas metas e objetivos foram logrados, mas, fundamentalmente, como o processo de elaboração da política conduziu aos seus resultados.

$\mathrm{O}$ trabalho está dividido em três seções. $\mathrm{Na}$ primeira seção, apresenta-se a origem do movimento do EAn. A segunda seção apresenta os ins-

\footnotetext{
1 Agradecemos aos pareceristas anônimos da Revista de Sociologia e Política pelas observações, que permitiram melhorar este artigo. Agradecemos também à Gabriela Chiareli, estagiária do GAPI (Grupo de Análise de Políticas de Inovação) do Departamento de Política Científica e Tecnológica (Dpct) da Universidade Estadual de Campinas (Unicamp) pela ajuda com a revisão do artigo.
}

trumentais analíticos do EAn. Destaque é dado ao ciclo da política (policy cycle), que orienta a análise da política pública de acordo com o momento de sua elaboração.

A terceira seção analisa a política do PATC. Nela se apresenta seus resultados, abordados sob duas perspectivas. A primeira considera o desempenho das empresas do setor de informática e telecomunicações instaladas no PATC; a segunda considera o desempenho das instituições de pesquisa e desenvolvimento (P\&D) locais, em especial o da Unicamp.

Nessa seção também são destacados dois aspectos que ajudam a compreender o porquê dos modestos resultados dessa Política passados trinta anos do início do processo de sua elaboração. O primeiro é o fato de ela ter sido emulada (transferida acriticamente) dos países de capitalismo avançado para um contexto de capitalismo periférico.

O segundo, que possui estreita relação com o primeiro, é ela ter sido formulada sem que as condições necessárias para sua implementação estivessem presentes na realidade do país e, conseqüentemente, na de Campinas. Isso caracteriza o PATC como uma política simbólica. 
A emulação desses arranjos institucionais como proposta de política pública, tal como a do PATC, implica os policy makers conceberem que os elementos que, se supunha, permitiam o desenvolvimento dessas experiências nos países de capitalismo avançado estivessem presentes na realidade brasileira e, invariavelmente, na de Campinas.

Como destacam as considerações finais, uma análise mais detida sobre a realidade brasileira mostraria que esses elementos possuem origens e trajetórias bastante distintas daquelas supostamente verificadas nos países de capitalismo avançado. Supostamente, pois, como destacado por Gomes (2001), mesmo nesses países, surgiram diversas considerações críticas de alguns autores acerca de tais elementos, suas interconexões e relevância para o desenvolvimento social.

\section{O ENFOQUE DE ANÁLISE DE POLÍTICAS:} SUAS ORIGENS E DESENVOLVIMENTO

Harold Lasswell, de acordo com Cavalcanti (2007), ainda durante os anos de 1930, foi quem iniciou um movimento nos Estados Unidos que se ocuparia dos estudos das políticas públicas: o movimento do EAn. Para ele, o objetivo do movimento era produzir, através da atividade acadêmica, "conhecimento 'de' e 'para' política", visando auxiliar à tomada de decisão do governo.

Somente após a II Guerra Mundial, mais precisamente no início dos anos 1950, o movimento começou a ganhar força nos Estados Unidos. A partir dessa década foram criados programas acadêmicos voltados ao entendimento das políticas públicas e instituições governamentais, que tinham a finalidade de entender as políticas públicas e suas qualidades (CAVALCANTI, 2007). Nos anos 1950 e 1960 as Ciências Econômicas eram as responsáveis pela maioria das informações e explicações sobre as políticas públicas (policy). Elas ressaltavam os aspectos de ordem econômica, ao passo que os de ordem social e as relações de poder (politics) eram deixados em segundo plano nas explicações das políticas (ROTH, 2006).

Segundo Ham e Hill (1993) e Roth (2006), o movimento nos EUA, durante os anos 1950 e 1960, contou com dois grupos de interessados. Um dos grupos estava ligado às instituições de governo que, diante da aparente impossibilidade de tratar os problemas colocados aos governos de sociedades industrializadas ocidentais, buscavam meios para solucionar os problemas públicos.
O outro grupo de interessados foi o dos pesquisadores acadêmicos, que, progressivamente, voltavam suas atenções às questões relacionadas às políticas públicas e que procuravam aplicar seu conhecimento à elucidação de tais questões. Mesmo diante dessa nova perspectiva de tratamento das políticas públicas, não houve nenhuma corrida súbita dos governantes em recorrer à pesquisa acadêmica, nem houve uma reordenação imediata da pesquisa acadêmica visando à Análise de Políticas.

O movimento não ficou restrito aos EUA. Países como Alemanha e Reino Unido criaram, a partir de meados dos anos 1970, programas acadêmicos e instituições de governo para analisarem as políticas públicas. Foi diferente a repercussão do movimento junto aos governos dos EUA e dos países europeus. O governo norte-americano deu mais atenção ao movimento e os analistas de políticas acadêmicos foram chamados a atuar nas agências governamentais. Na Europa isso quase não ocorreu (HAM \& HILL, 1993).

Nos anos 1980, apesar de ter havido uma tendência de deslocamento dos termos do debate sobre as políticas públicas, o interesse no EAn continuou a desenvolver-se. O ataque ao setor público, feito pelas instituições internacionais (como o Banco Mundial (BIRD) e o Fundo Monetário Internacional (FMI)), que culminou em novembro de 1989 no Consenso de Washington e a recomendação de aplicarem-se as técnicas de gestão do setor privado no setor público, contribuíram para enfraquecer o movimento (idem). Mesmo diante dessas transformações que vinha vivenciando o setor público, foi nos anos 1980 que o EAn disseminou-se por vários países, incluindo o Brasil.

No Brasil os estudos envolvendo o EAn são ainda bastante incipientes. Neste país, o movimento sofre de grande fragmentação organizacional e temática e tem uma institucionalização ainda precária (CAVALCANTI, 2007). Os estudos atualmente desenvolvidos no Brasil dão ênfase às estruturas e instituições ou à caracterização dos processos de negociação de políticas de setores específicos. Eles consideram apenas os efeitos das políticas públicas e são, antes de qualquer coisa, de natureza descritiva (FREY, 2000).

No movimento estão presentes, fundamentalmente, duas concepções: uma é a da análise das políticas; e, a outra, é a da análise para políticas 
(HAM \& HILL, 1993). A primeira perspectiva chama a atenção para o EAn como uma atividade acadêmica, que se preocupa em somente compreender as políticas. A segunda chama a atenção do EAn como sendo uma atividade governamental, preocupada principalmente em contribuir para solucionar problemas públicos. Essas duas concepções existem devido aos interesses dos grupos que compõem o movimento (instituições de governo e academia).

Entre esses grupos existem aqueles que defendem que o objetivo do EAn deve ser o de melhorar o entendimento da política (policy) e aqueles que defendem o objetivo de melhorar a qualidade da política. Outros, ainda, defendem ambos os objetivos (idem). Ham e Hill destacam alguns estudiosos que discutem essas concepções e qual seria o objetivo do EAn. Entre eles, ganhou destaque Thomas Dye, para quem as preocupações dos analistas de políticas, tanto os acadêmicos como os de governo, deveriam estar voltadas ao que o governo faz (Dye apud HAM \& HILL, 1993).

Dye corrobora as visões de uma série de outros estudiosos que argumentavam que o Enfoque de Análise de Políticas deveria ser uma atividade tanto descritiva (melhorar o entendimento da política) quanto prescritiva (melhorar a qualidade da política). Mas destaca que a defesa de uma política pública e a análise de uma política são tarefas que devem ser realizadas separadamente (Dye apud HAM \& HILL, 1993). Outro estudioso é Lasswell, que mantinha muitas esperanças na contribuição que os analistas de políticas poderiam dar à melhoria do entendimento das políticas públicas (Lasswell apud HAM \& HILL, 1993).

Lasswell afirmava que os analistas de políticas acadêmicos não deveriam nem se engajar em "tempo integral" na prática política (policy) nem empregar seu tempo aconselhando os governantes em questões de cunho imediato (politics). Os analistas acadêmicos deveriam concentrar-se em questões maiores e comunicar suas investigações aos governantes por intermédio de conferências (Lasswell apud HAM \& HILL, 1993).

A orientação prescritiva do Enfoque foi também enfatizada por Aaron Wildavsky. Ele rejeitava a idéia de que seria possível chegar a uma única definição do Enfoque. Ao invés de tentar definir o que seria o Enfoque, ele destacou sua principal característica: ser uma atividade centrada em problemas públicos (Wildavsky apud HAM \& HILL, 1993).

$\mathrm{O}$ analista acadêmico deveria engajar-se em analisar os problemas públicos e propor soluções para eles. Ou seja, o objetivo do EAn seria o de melhorar o entendimento da política e, com isso, ajudar a melhorar sua qualidade. Todavia, contribuir ativamente para converter as soluções apresentadas na análise em políticas públicas (policy) seria uma atividade que extravasaria o trabalho do analista acadêmico (Wildavsky apud HAM \& HILL, 1993).

Já os objetivos do Enfoque para os analistas de políticas no governo (ligado às instituições de governo) variam consideravelmente. Meltsner, em 1976, identificou três tipos de analistas de políticas ao considerar suas funções na burocracia federal norte-americana: o analista técnico; o político; e o empreendedor (Meltsner apud HAM \& HILL, 1993). O primeiro, o técnico, estaria interessado em produzir pesquisas de boa qualidade. Ele seria, essencialmente, um acadêmico em residência burocrática. O segundo, o político, estaria preocupado com a obtenção de influência e promoção pessoal. E o empreendedor estaria interessado no uso da análise para influenciar a política (policy) e melhorar o impacto dela (Meltsner apud HAM \& HILL, 1993).

Um ponto que deve observar-se é o fato de analistas acadêmicos estarem penetrando cada vez mais o âmbito do governo. Isso é verdade não apenas nos Estados Unidos, mas também na Europa. Como conseqüência, a divisão entre analistas de políticas acadêmicos e analistas de políticas ligados às instituições de governo está cada vez mais difusa. Analistas de políticas acadêmicos têm também usado, em alguns casos, suas especializações para assessorarem grupos de pressão social a perseguirem seus ideais políticos (HAM \& HILL, 1993).

Isso ocorre porque, ao contrário do que Lasswel, Dye e Wildavsky levam a supor - de que os trabalhos acadêmicos são desprovidos de qualquer valor social (econômico, político etc.) , as práticas acadêmicas (de pesquisa) não são desprovidas de valores sociais (LACEY, 1998; DAGNINO, 2004). Mesmo para Ham e Hill (1993), o enfoque não é isento de valores sociais. A idéia de que a análise seja científica, imparcial e 
neutra é um mito. Toda pesquisa é, inevitavelmente, influenciada pelas crenças e suposições do analista.

\section{INSTRUMENTAIS ANALÍTICOS DO ENFOQUE DE ANÁLISE DE POLÍTICAS}

O estudo da política pública, como unidade de análise, conta com o instrumental metodológico do EAn. Para Dye, o EAn pode ser considerado como uma investigação sistemática que estuda o que os governos fazem, por que fazem e a diferença que isso faz à sociedade. Analisar uma política pública implica sua descrição e a explicação das causas e conseqüências das atitudes do governo (Dye apud CAVALCANTI, 2007).

Para superar-se a abordagem dicotômica nos estudos das políticas públicas no Brasil, que ora dá prioridade à dimensão institucional (policy), ora à dimensão político-processual (politics), é necessário que essas dimensões não sejam dissociadas. Não se pode estudar a dimensão policy (política pública) sem que se considere as dimensões de politics (relações de poder). E é justamente o instrumental (a metodologia) do EAn que possibilita tratar a dimensão material (policy) conjuntamente com a dimensão política (politics) (FREY, 2000).

Para que essa proposta seja levada adiante, o analista de políticas tem que dispor de "ferramentas analíticas" capazes de auxiliá-lo. Entre os referenciais analíticos usados para entender as políticas públicas e o seu processo de elaboração (HAM \& HILL, 1993), merece destaque o ciclo da política.

\section{III.1. O ciclo da política}

Existe uma variedade significativa de insumos analíticos (ou "ferramentas analíticas") que podem ser utilizados para a análise de uma política pública. Entre eles, merece ser destacado o ciclo da política, que decompõe o processo de elaboração de políticas em momentos.

No plano analítico, ou teórico, a decomposição de uma política em um ciclo, composto por momentos, aparece na literatura ora como um processo que representa "a vida real" de uma política pública, ora como um recorte analítico que "idealiza a vida de uma política" (CAVALCANTI, 2007). A decomposição da política em momentos é entendida como uma ferramenta de análise que deve ser utilizada para a compreensão do processo de elaboração de uma política pública.
O ciclo da política é, propriamente, um dispositivo analítico utilizado para o estudo de uma dada política. Construído para fins de modelação, ordenamento, explicação e prescrição do processo de elaboração de política, ele pertence a uma ordem mais lógica do que cronológica (idem). No ciclo da política, a política pública deve ser entendida como um processo contínuo e dinâmico, que, para efeito de análise, é composto por momentos $^{2}$. No que tange à análise desse processo é importante ressaltar que cada momento possui: i) atores; ii) restrições; iii) decisões; iv) desenvolvimento; v) resultados próprios. Embora cada momento possua seus componentes, eles não devem ser entendidos como independentes (idem).

O ciclo da política parte do pressuposto de que o "agir público" na resolução de problemas públicos pode ser dividido em momentos parciais. Esses momentos correspondem a uma seqüência de elementos que podem ser examinados no que diz "respeito às constelações de poder, às redes políticas e sociais e às práticas político-administrativas que se encontram tipicamente em cada fase" (FREY, 2000). Desse modo, a decomposição de uma política em momentos é uma ferramenta útil, uma vez que permite compreender a política através de uma análise processual.

O processo de elaboração da política desenvolve-se em momentos. A política pública é elaborada em um processo cíclico e reiterativo que pode ser dividido em cinco momentos: i) da construção de um problema público; ii) da formulação da política; iii) da tomada de decisão; iv) da implementação da política; v) da avaliação da política. Todavia, os momentos do processo de elaboração da política não ocorrem de maneira tão ordenada e seqüencial quanto possa parecer (ROTH, 2006).

\section{III.2. O momento da construção do problema pú- blico}

De maneira geral, no que diz respeito ao processo de elaboração das políticas, ele ocorre quando uma questão ou situação transforma-se em um problema público, que é inserido na agenda de

\footnotetext{
2 Momento é uma instância repetitiva pela qual passa um processo encadeado e contínuo, que não tem princípio nem fim bem demarcados (MATUS, 1996). O conceito não tem uma característica meramente cronológica e indica instância, ocasião, circunstância ou conjuntura pela qual passa um processo contínuo ou em cadeia, sem começo nem fim bem definidos (CAVALCANTI, 2007).
} 
governo. Esse é o momento da construção de um problema público (ver Quadro 1). Uma questão é definida quando o poder público "percebe" a necessidade de tomar posição a respeito de um determinado assunto. Essa questão torna-se um problema público quando o poder público reconhece a necessidade de elaborar uma política pública para sua resolução.

O reconhecimento de um problema público não é um dado objetivo. Todo problema público é construído socialmente. Ele é reconhecido e aceito como tal por meio de conflitos entre os atores sociais: alguns atores lutam politicamente (politics) para fazer com que outros reconheçam uma dada situação social como um problema público e para que o governo intervenha para solucioná-lo. A definição do que vem a ser um problema público está, portanto, ligada de maneira íntima ao mode- lo cognitivo (modelização da realidade) dos atores envolvidos no processo. Dessa forma, o problema público representará os interesses desses atores (idem).

O fundamental nesse momento é entender quem são os atores que participam do processo e como eles envolvem-se no encaminhamento e no tratamento de um problema público. Nesse momento existem dois elementos, que não podem ser dissociados: o primeiro é o reconhecimento de um problema público; o segundo é a inscrição desse problema na agenda de governo para que se intervenha politicamente sobre ele. Inserir um problema na agenda de governo significa que ele poderá entrar na agenda decisória (aqueles problemas que sofrerão de fato intervenção do Estado para a sua resolução).

\section{QUADRO 1 - MOMENTO DA CONSTRUÇÃO DE UM PROBLEMA}

\begin{tabular}{|cc|}
\hline $\begin{array}{c}\text { ELEMENTOS ORIENTADORES } \\
\text { DA ANÁLISE }\end{array}$ & Contexto em que surge uma questão \\
& Atores que participam do processo de encaminhamento da questão \\
& Questão que atinge o status de problema público \\
\hline
\end{tabular}

FONTE: os autores, a partir de Ham e Hill (1993), Roth (2006) e Cavalcanti (2007).

Quando se reconhece um problema público como passível de intervenção política surgem propostas para resolvê-lo. Por meio dos conflitos entre os atores políticos que participam do processo de construção do problema, em defesa de seus interesses políticos, uma resposta a ele deve configurar-se.

\section{III.3. O momento da formulação das propostas} de política

A definição de um problema pode ser a chave para o seu tratamento posterior. Logo, ao definir uma questão como um problema público está aceitando-se a idéia de que se pode intervir sobre ele. E que, portanto, é necessário definir propostas capazes de atender às suas especificidades (idem).

O momento da formulação é justamente aquele em que as propostas para a resolução do problema público configuram-se. Ele inicia-se quando os atores envolvidos no processo de elaboração da política, "conjuntamente" (concordando ou não, barganhando ou não) começam a definir as propostas de políticas que poderão ser viabilizadas pelo poder público (CAVALCANTI, 2007). Esse momento pode ser assimilado a um funil: nele entram inicialmente muitas propostas para a resolução de um problema e, pouco a pouco, somente uma é aceita, mesmo que haja hibridação entre elas.

Em função do grau de abertura do sistema político, atuam vários atores (governantes, comunidade de pesquisa, movimentos sociais, administradores e lobistas), que podem impor diversos ritmos à formulação da política. Em todo caso, esse momento não é linear. No momento da formulação da política pública (ver Quadro 2), as propostas possíveis para solucionar o problema público começam a ser esboçadas. São apresentados os objetivos e as metas das políticas públicas e as diretrizes para sua resolução (ROTH, 2006). A formulação da política é um dos mais importantes momentos do processo de elaboração de políticas, porque é quando se revelam as preferências dos atores e manifestam-se os seus interesses (CAVALCANTI, 2007).

As preferências dos atores se manifestam nas propostas de solução para o problema que cada um deles defende e que, obviamente, os beneficiaria. Portanto, no momento da formulação, cada 
ator terá sua preferência acerca de como atacar a situação-problema que foi identificada, de modo que as metas e os objetivos apresentados sejam aquelas que atendam aos seus interesses. A formulação exige que diretrizes sejam apresentadas a fim de lograrse os objetivos e metas das políticas.

QUADRO 2-MOMENTO DA FORMULAÇÃO

\begin{tabular}{|cc|}
\hline & Propostas de solução \\
ELEMENTOS ORIENTADORES DA & Atores envolvidos no processo \\
ANÁLISE & Ator dominante \\
& Interesses \\
& Metas e objetivos da política \\
& Diretrizes da política \\
\hline
\end{tabular}

FONTE: os autores, a partir de Ham e Hill (1993), Roth (2006) e Cavalcanti (2007).

Conforme exposto por Ham e Hill (1993), há casos em que as políticas são formuladas sem que as condições para sua implementação estejam presentes. Nesse caso, as políticas formuladas podem ser consideradas políticas simbólicas. Qualquer sistema no qual a formulação de políticas e as condições necessárias para sua implementação estejam claramente separadas, ou ausentes, - uma divergência entre legislativo e executivo; um desacordo entre os atores envolvidos no processo; proposta de política pública em que não há recursos financeiros suficientes para sua implementação - provê oportunidades para que elas tornem-se simbólicas.

Adotando uma perspectiva um tanto distinta da apresentada por Ham e Hill, considera-se política simbólica também aquelas políticas que são formuladas sem que se tenha clareza da separação entre a formulação e as condições necessárias para sua implementação. Pois, assim como ocorre quando há clareza dessa separação, naqueles casos em que ela não é evidente, o fato de a política ser formulada acaba levando a sociedade a acreditar que o governo (ou o ator dominante) está tomando atitudes diante de um problema público. Nesse sentido, a política acaba servindo mais para que a sociedade mantenha o apoio político ao governo, ou ao ator dominante no processo, do que para atuar sobre os problemas sociais.

Há casos em que o ator que formula uma política tem por propósito não a sua implementação, e muito menos o êxito dela. Ele busca a obtenção do apoio político que a declaração de que a política será implementada pode causar, o que a caracteriza como uma política simbólica. $\mathrm{O}$ efeito buscado com as políticas simbólicas é, então, a repercussão que o simples enunciado de sua existência pode causar (ROTH, 2006). E seu impacto, em termos do apoio político obtido pelo ator que a formula, é tanto maior quanto maior a sua capacidade que possui de criar um "fato político". A qual depende de seu acesso aos meios de comunicação e de formação da opinião pública (ou de setores específicos da sociedade).

\section{III.4. O momento da tomada de decisão}

O momento da tomada de decisão (ver Quadro 3) é considerado como aquele em que se elege uma ou mais propostas, formuladas no momento anterior, para serem implementadas. Ou seja, o momento da tomada de decisão, no processo de elaboração da política, pode ser definido como uma escolha da proposta de política que melhor resolveria o problema (CAVALCANTI, 2007).

QUADRO 3-MOMENTO DA TOMADA DE DECISÃO

\begin{tabular}{|cc|}
\hline $\begin{array}{c}\text { ELEMENTOS ORIENTADORES DA } \\
\text { ANÁLISE }\end{array}$ & Escolha da proposta \\
& Atores que participam do processo \\
& Ator dominante \\
& Legitimação da proposta (proposta que se tornará política \\
pública)
\end{tabular}

FONTE: elaboração própria, a partir de Ham e Hill (1993), Roth (2006) e Cavalcanti (2007). 
De acordo com Roth (2006), seriam cinco os modelos analíticos mais conhecidos sobre tomada de decisão: i) o modelo de decisão racional absoluta; ii) o modelo de decisão racional limitada; iii) o modelo da anarquia organizada; iv) o modelo incremental ou de ajustes marginais; v) o modelo da escolha pública (public choice).

i. No modelo de decisão racional absoluta, o tomador de decisão (individual ou coletivo) atua utilizando critérios de racionalidade. É um modelo descritivo e prescritivo, pois nele o tomador de decisão dispõe de todas as informações necessárias para a tomada de decisão e, diante disso, escolhe e prescreve qual a melhor opção entre as demais. Esse modelo de tomada de decisão estabelece quais os valores devem ser elevados ao máximo e qual é a melhor alternativa para a resolução do problema público. A escolha de uma alternativa em meio a várias outras é feita por uma análise abrangente e detalhada de cada uma delas e de suas possíveis conseqüências. Esse modelo parte da premissa irrealista ou ingênua de que existe informação perfeita e de que o processo de tomada de decisão não está sujeito ao peso das relações assimétricas de poder (CAVALCANTI, 2007).

ii. O modelo de decisão racional limitada aponta que o tomador de decisão nunca toma uma decisão seguindo uma lógica racional absoluta. As limitações na tomada de decisão racional fazem com que o tomador de decisão escolha aquela solução que lhe pareça mais satisfatória. Trata-se, então, de buscar um meio termo entre a análise do problema e a urgência de oferecer uma solução aceitável. Dessa forma, privilegia-se uma solução em detrimento de outra. De modo geral, o que o tomador de decisão busca não é a melhor solução para o problema, mas evitar a pior. Nesse modelo, os critérios aplicados à decisão são frutos de uma mescla de intuição e razão - quer dizer, um juízo razoável — mais do que de razão pura. O exercício da razão encontra-se limitado pelo contexto social, político e cognitivo no qual atua o tomador de decisão (ROTH, 2006).

iii. $\mathrm{O}$ modelo da anarquia organizada pode ser entendido como o inverso do modelo de decisão racional absoluta. Ele pretende explicar o mundo da incerteza e da ambigüidade. Considera que a influência das instituições sobre as decisões é baixa ou quase nula. Três elementos caracterizam esse processo de tomada de decisão: i) valores e objetivos apresentam-se de forma ambígua; ii) conhecimento e informações disponíveis são incompletos, fragmentados e incertos; iii) processo de decisão complexo e, em grande medida, simbólico (idem). Nesse modelo, as condições de ambigüidade e de incerteza são reinantes no processo. E, também, as atividades, os procedimentos, a participação e as competências dos tomadores de decisão são vagas e mudam constantemente (idem).

iv. O modelo incremental implica a maioria das decisões políticas não serem mais do que ajustes às políticas públicas já existentes. É o triunfo do pragmatismo e do reformismo, da política dos pequenos passos, como estratégia que resulta em acordos dentro de um universo plural. Segundo esse modelo, nenhum tomador de decisão poderia aplicar realmente o modelo racional. O que ele pode fazer é aplicar um método instintivo de comparação entre soluções empíricas. Ao contrário do que ocorre com o modelo de decisão racional absoluta, em que a racionalidade é a priori, no modelo incremental ela é $a$ posteriori. Ou seja, a racionalidade emerge da prática política. É o jogo das pressões e das contrapressões dos atores, que utilizam suas experiências adquiridas no processo de elaboração da política, que vai definir qual a proposta de política será apresentada (idem).

v. O modelo da escolha pública caracteriza-se por ser uma tentativa de aplicação da teoria econômica no terreno da política (politics). Esse modelo contraria a idéia de que os atores envolvidos no processo de elaboração da política trabalham de maneira altruísta na busca do interesse público comum. Os atores políticos envolvidos no processo são comparados aos empresários privados: o apoio às decisões políticas e às políticas públicas encontra sua motivação e explicação na maximização dos interesses políti- 
cos dos atores. Em uma perspectiva mais ampla, as observações acima podem ser aplicadas não somente aos atores políticos individuais, mas também aos grupos organizados de atores. Esses grupos organizados defenderiam, então, seus interesses buscando manter ou conquistar posições e vantagens (idem). Adotando uma perspectiva um tanto distinta da dos partidários da Escolha Pública, que destaca a existência de classes sociais na sociedade capitalista, há que se ressaltar que, entre esses interesses, estão aqueles que correspondem ao de determinadas classes sociais.

\section{III.5. O momento da implementação}

No momento da implementação (ver Quadro 4) da política pública, até então feita quase que exclusivamente de discursos e de palavras, transformase em ações concretas, em realidade palpável. Esse momento é visto, de modo geral, como a "efetivação" da política: quando a solução do problema público é posta em prática. Depois de escolhida a proposta política, as instituições públicas ou privadas iniciam a sua implementação. Esse é o momento do processo de elaboração da política em que existe a preocupação de concretizar as metas e objetivos da política (CAVALCANTI, 2007).

\section{QUADRO 4 - MOMENTO DA IMPLEMENTAÇÃO}

\begin{tabular}{|c|c|}
\hline & Anúncio de resultados e metas \\
ELEMENTOS ORIENTADORES DA & Atores que participam do processo \\
ANÁLISE & Atores dominantes \\
& Instrumentos legais \\
& Objetivos da política pública \\
& Diretrizes \\
\hline
\end{tabular}

FONTE: os autores, a partir de Ham e Hill (1993), Roth (2006) e Cavalcanti (2007).

A proposta proveniente da tomada de decisão representa apenas a intenção de solucionar o problema público. Para que essa intenção se transforme em ações concretas, se promulgam instrumentos legais (leis, decretos, normas, programas e planos).

O processo de implementação é um momento especialmente problemático. É nele em que emergem as negociações que não foram levadas a termo entre os atores políticos ou que foram propositalmente deixadas em suspenso. Isso denota o caráter dinâmico e complexo do processo (idem).

\section{III.6. O momento da avaliação}

$\mathrm{O}$ último momento, o da avaliação, remete à preocupação com o processo de elaboração da política em seu conjunto, constituído pelos momentos da construção de um problema público, da formulação, da tomada de decisão e o momento da implementação da política pública (ver Quadro 5). O momento da avaliação, diferentemente do Enfoque da Avaliação de Políticas, analisa o processo de elaboração da política como um todo (DIAS \& DAGNINO, 2006).

\section{QUADRO 5 - MOMENTO DAAVALIAÇÃO DAPOLÍTICAPÚBLICA}

\begin{tabular}{|cc|}
\hline ENFOQUE DE ANÁLISE DE POLÍTICAS \\
\hline Momento da avaliação da política pública & Momento da construção de um problema \\
& Momento da formulação \\
& Momento da tomada de decisão \\
& Momento da implementação \\
\hline
\end{tabular}

FONTE: os autores, a partir de Ham e Hill (1993), Roth (2006) e Cavalcanti (2007). 
No EAn há uma diversidade de tipos de avaliação, que podem ser classificados em quatro categorias (ver Quadro 6): a primeira refere-se à ocasião em que se aplica a avaliação; a segunda está relacionada à função da avaliação; a terceira, refere-se ao que se avalia; e, a quarta, refere-se ao sujeito (ator) que realiza a avaliação.

Na primeira categoria (ocasião da avaliação) encontram-se as avaliações ex-ante, concomitante (durante) e ex post. A primeira deve ser realizada antes de a política ser colocada em prática. A segunda deve acontecer durante o processo de elaboração da política. E a última deve ser realizada no final do processo de elaboração (CAVALCANTI, 2007).

Sobre a função da avaliação (segunda categoria), os termos mais comumente encontrados são: avaliação formativa e avaliação somativa. Essas duas funções estão correlacionadas com o objetivo da avaliação, que poderia ser informar (formativa) sobre a política, que ocorre normalmente após o termino da implementação. Ou fornecer insumos (somativa) para a elaboração da política, que ocorre durante o processo.
O que se avalia (terceira categoria) pode ser interpretado como quais são os objetivos da avaliação. Nesse caso, podem ser identificados basicamente três objetivos: i) avaliar o desenho da política, em que são observados os elementos relacionados ao momento de formulação da política, o processo de definição do problema e o estabelecimento da agenda decisória; ii) avaliar o processo de implementação, em que o foco está em entender como funciona a política pública; iii) avaliar os resultados da política, em que se examinam os produtos (outputs) e os efeitos (outcomes) da política (idem).

Sobre os sujeitos (atores) que realizam a avaliação (a quarta categoria), eles são basicamente classificados em três grupos: a avaliação interna, muitas vezes denominada de auto-avaliação, que é realizada pelos responsáveis pela elaboração da política; avaliação externa, que se opõe à anterior. Nela, os avaliadores são aqueles que estão fora do processo de elaboração da política. Normalmente são profissionais contratados para realizar a avaliação; na avaliação mista, como o nome diz, participam avaliadores externos e internos ao processo de elaboração da política em questão (idem).

QUADRO 6 - CATEGORIAS DE AVALIAÇÃO NO ENFOQUE DE ANÁLISE DE POLÍTICAS

\begin{tabular}{|c|c|c|c|}
\hline $\begin{array}{c}\text { OCASIÃO DA } \\
\text { AVALIAÇÃO }\end{array}$ & OBJETIVO DA AVALIAÇÃo & $\begin{array}{c}\text { FUNÇÃO DA } \\
\text { AVALIAÇÃO }\end{array}$ & ANALISTA \\
\hline Ex-ante & Informações sobre a construção do & Formativa e/ou & Interno, externo \\
& problema; formulação e tomada de decisão & ou misto \\
Concomitante & Informações sobre a implementação & $\begin{array}{c}\text { Formativa e/ou } \\
\text { somativa }\end{array}$ & $\begin{array}{c}\text { Interno, externo } \\
\text { ou misto }\end{array}$ \\
& Informações sobre o processo de & Formativa e/ou & Interno, externo \\
Ex-post & elaboração das políticas & somativa & misto \\
\hline
\end{tabular}

FONTE: os autores, a partir de Cavalcanti (2007).

A utilização dos tipos contidos em cada categoria vai depender da ocasião, assim como da função, dos objetivos e dos atores envolvidos no processo de elaboração da política. Apesar de variarem a função e os objetivos da avaliação, o viés metodológico do analista de políticas deve conduzi-lo a explicar o processo de elaboração da política com base em duas dimensões. A primeira é a dos atores intervenientes no processo de tomada de decisão. Nessa dimensão, o analista de políticas deve entender como o ator dominante atua no sentido de fazer valer seus interesses. A segunda dimensão é a que se ocupa da identificação das falhas (ou déficits) de implementação, vis-àvis às de formulação.
Por mais que possam estar asseguradas as condições para a implementação bem-sucedida, uma política mal formulada (apoiada em um modelo cognitivo pouco coerente com a realidade, um modelo cognitivo irrealista) jamais poderá ser bem implementada (DIAS \& DAGNINO, 2006). Se isso ocorrer, reúne as condições para que a política seja simbólica.

A avaliação, no EAn, deve ser vista como instrumento (ferramenta) inerente ao próprio processo de elaboração da política pública. Como tal, ao emitir juízo e valor sobre uma dada política, não deve considerar somente os resultados ou impactos de forma desconectada dos outros momentos que a cercam. A avaliação deve voltar-se à políti- 
ca de maneira conjunta e inseparável. Portanto, deve alimentar o debate democrático favorecendo as práticas mais participativas no processo de elaboração de uma política (CAVALCANTI, 2007).

\section{UMAANÁLISE DA POLÍTICA PÚBLICADO PÓLO E PARQUE DE ALTA TECNOLOGIA DE CAMPINAS (PATC)}

IV.1. Os resultados da politica do PATC - A relevância da P\&D local para os setores produtivos

Souza e Garcia (1998) realizaram um estudo sobre o arranjo produtivo de indústrias de alta tecnologia de Campinas e região. Segundo eles, Campinas e região possuem um conjunto de empresas de alta tecnologia pertencentes, principalmente, aos setores destacados na Tabela 1 .

Como observado na Tabela, as empresas consideradas de alta tecnologia não se destacam na estrutura industrial local. Se considerado o número total de estabelecimentos industriais, que é de 4620 no ano de 1996, em Campinas e região, somados os setores destacados eles correspondem a $4,2 \%$ desse total. No ano de 2005 observar-se-á que o número de estabelecimentos industriais é 15 864, ou seja, 3,5 vezes maior que o de 1996. Porém, o peso relativo dos setores destacados, em 2005, foi reduzido para $3,5 \%$ do total.

TABELA 1 - NÚMERO DE ESTABELECIMENTOS E PESSOAL OCUPADO NA REGIÃO DE CAMPINAS EM SETORES SELECIONADOS (1996 E 2005)

\begin{tabular}{|c|c|c|c|c|c|c|c|c|}
\hline \multirow{3}{*}{ Setor CNAE } & \multicolumn{4}{|c|}{$\begin{array}{c}\text { ESTABELECIMENTOS DA } \\
\text { INDÚSTRIA }\end{array}$} & \multicolumn{4}{|c|}{ PESSOAL OCUPADO } \\
\hline & \multicolumn{2}{|c|}{$N}$. & \multicolumn{2}{|c|}{$\%$} & \multicolumn{2}{|c|}{$N$} & \multicolumn{2}{|c|}{$\%$} \\
\hline & 1996 & 2005 & 1996 & 2005 & 1996 & 2005 & 1996 & 2005 \\
\hline $\begin{array}{l}\text { Fabricação de máquinas e } \\
\text { equipamentos de sistemas } \\
\text { eletrônicos para processamento de } \\
\text { dados }\end{array}$ & 16 & 33 & 0,3 & 0,20 & 712 & 3599 & 0,5 & 0,58 \\
\hline $\begin{array}{l}\text { Fabricação de material elétrico para } \\
\text { veículos - exceto baterias }\end{array}$ & 8 & 28 & 0,2 & 0,17 & 1227 & 3827 & 0,8 & 0,62 \\
\hline $\begin{array}{l}\text { Fabricação de material eletrônico } \\
\text { básico }\end{array}$ & 20 & 68 & 0,4 & 0,42 & 626 & 3577 & 0,4 & 0,58 \\
\hline $\begin{array}{l}\text { Fabricação de aparelhos e } \\
\text { equipamentos de telefonia e } \\
\text { radiotelefonia e de transmissores de } \\
\text { televisão e rádio }\end{array}$ & 17 & 25 & 0,4 & 0,15 & 550 & 5621 & 0,4 & 0,91 \\
\hline $\begin{array}{l}\text { Fabricação de aparelhos e } \\
\text { instrumentos para usos médico- } \\
\text { hospitalares, odontológicos }\end{array}$ & 19 & 82 & 0,4 & 0,51 & 631 & 2251 & 0,4 & 0,36 \\
\hline $\begin{array}{l}\text { Fabricação de aparelhos e } \\
\text { instrumentos de medida, teste e } \\
\text { controle }\end{array}$ & 7 & 7 & 0,2 & 0,04 & 620 & 205 & 0,4 & 0,03 \\
\hline $\begin{array}{l}\text { Fabricação de máquinas, aparelhos } \\
\text { e equipamentos de sistemas } \\
\text { eletrônicos dedicados à automação } \\
\text { industrial e controle do processo } \\
\text { produtivo }\end{array}$ & 4 & 40 & 0,1 & 0,25 & 17 & 567 & 0,0 & 0,09 \\
\hline $\begin{array}{l}\text { Fabricação de aparelhos, } \\
\text { instrumentos e materiais ópticos, } \\
\text { fotográficos e cinematográficos }\end{array}$ & 34 & 29 & 0,7 & 0,18 & 973 & 2211 & 0,7 & 0,35 \\
\hline $\begin{array}{l}\text { Fabricação de peças e acessórios } \\
\text { para veículos automotores }\end{array}$ & 70 & 234 & 1,5 & 1,47 & 13948 & 56921 & 9,5 & 9,25 \\
\hline $\begin{array}{l}\text { TOTAL DA INDÚSTRIA DE } \\
\text { TRANSFORMAÇÃO }\end{array}$ & 4620 & 15864 & 100 & 100 & 146203 & 615276 & 100 & 100 \\
\hline
\end{tabular}

FONTES: os autores, a partir de Souza e Garcia (1998) para 1996 e Seade (2006) para 2005.

NOTA: CNAE: Classificação Nacional de Atividades Econômicas. 
Mesmo no ano de 2005 esses setores não possuíam grande destaque na estrutura industrial local. Mesmo alguns setores tendo dobrado o número de estabelecimentos entre 1998 e 2005, o peso relativo deles decaiu ou, em alguns casos, manteve-se constante. O mesmo ocorreu em relação ao peso relativo do pessoal ocupado.

Dos setores destacados por Souza e Garcia (1998), os que mais englobam as empresas de alta tecnologia de Campinas e região são os de fabricação de máquinas e equipamentos de sistemas eletrônicos para processamento de dados; fabricação de material eletrônico básico; fabricação de aparelhos e equipamentos de telefonia e radiotelefonia e de transmissores de televisão e rádio; fabricação de máquinas, aparelhos e equipamentos de sistemas eletrônicos dedicados à automação industrial.

Uma avaliação desses setores, feita por Souza e Garcia (idem), envolveu 13 empresas que atuavam nos ramos da prestação de serviços e de fabricação de equipamentos para telecomunicações e informática. No que tange ao ano de estabelecimento das unidades produtivas, verificou-se que seis das 13 empresas foram estabelecidas em um período anterior à década de 1990 . Mesmo assim, foi grande (cinco das 13) o número de empresas que se estabeleceram em Campinas, ou região, a partir de 1995.

Em relação à origem do capital, os autores incorporaram na amostra tanto empresas domésticas como estrangeiras. Das 13 empresas pesquisadas, oito eram subsidiárias de empresas estrangeiras, enquanto que as cinco restantes eram domésticas. Em relação ao porte das empresas, seis eram empresas de grande porte, quatro, de médio e três eram pequenas empresas. Não coincidentemente, o porte das empresas estrangeiras foi, em geral, maior que o das domésticas que atuam na região nos setores selecionados. Muitas dessas empresas de médio e pequeno portes, especialmente entre as prestadoras de serviços, resultaram de spin-offs das instituições de P\&D locais (idem).

Já entre as subsidiárias das empresas estrangeiras, muitas delas resultaram do processo de desnacionalização da indústria brasileira. Se antes do processo de liberalização da economia brasileira, iniciado na primeira metade dos anos 1990, as empresas domésticas tinham uma participação relevante nos setores investigados, no período recente essa participação vem diminuindo aceleradamente. Aumentou a importância do capital estrangeiro em Campinas e região, o que ocorreu por meio de fusões e aquisições e devido aos novos investimentos diretos das empresas estrangeiras (idem).

Os fatores que levaram as empresas estrangeiras a instalarem-se em Campinas e região estavam vinculados, principalmente, com a vasta infraestrutura logística que cerca a região e com um complexo e integrado sistema viário. Devido, inclusive à existência do Aeroporto Internacional de Viracopos, que recebe grande parte do movimento de cargas provenientes do exterior (idem).

As grandes empresas também investiram em processos internos de treinamento de pessoal. Isso levou à formação de um contingente razoável de trabalhadores especializados, com habilidades tácitas e específicas a esses setores (idem). É provável que isso tenha ocorrido porque o perfil do profissional formado pelas universidades, que eram destacadas como o lócus para a formação de mão-de-obra qualificada, não correspondia ao perfil requerido pelas empresas.

Para as empresas, o principal diferencial da região de Campinas era sua estrutura logística e não o potencial de $\mathrm{P} \& \mathrm{D}$ instalado no município. As interações entre as empresas de capital estrangeiro (aquelas que mantinham alguma atividade de $P \& D)$ com as instituições de $P \& D$ locais eram de caráter eminentemente formal, para atender às contrapartidas ou exigências legais, como as da Lei de Informática (idem).

Outro ponto importante destacado na pesquisa de Souza e Garcia é o de que entre os principais investimentos anunciados para a cidade de Campinas, entre os anos 1997 e 1998, 12 deles eram de empresas estrangeiras e um de empresa doméstica, que iriam instalar suas plantas industriais no município. Entre essas empresas, podese destacar Lucent Technologies, Nortel Telecomm, Compaq, Motorola, DEC, Avex, SCI Systems e GE Plastics, que são consideradas exemplos de empresas de alta tecnologia. Como destacam Souza e Garcia, também para essas empresas (além das 13 investigadas) os principais fatores para sua instalação em Campinas estavam ligados à infra-estrutura viária da região e à presença do Aeroporto de Viracopos. 
Nesse sentido, também para essas empresas a presença de um complexo aparato de ciência e tecnologia $(C \& T)$ na região tinha claramente uma importância secundária. Para elas, o principal diferencial da região de Campinas era sua estrutura logística (idem).

Um aspecto que também marca a interação das pequenas e médias empresas localizadas em Campinas com as instituições de P\&D está relacionado às "filhas da Unicamp", que é como são chamadas as empresas spin-offs da Unicamp. Segundo dados do Programa Pesquisa Inovativa na Pequena e Micro-Empresa (PIPE) ${ }^{3}$, da Fundação de Amparo à Pesquisa do Estado de São Paulo (Fapesp), de 1997 a 2007, o Programa concedeu financiamento à 330 pequenas e médias empresas $^{4}$ do estado de São Paulo. Dessas, 64 localizavam-se em Campinas, o que corresponde a 19,4\% do total de empresas. Das 64 empresas, 31 eram "filhas da Unicamp" (FAPESP, 2008). Ou seja, $48,5 \%$ das empresas beneficiadas com os financiamentos do PIPE já tinham suas atividades de pesquisa diretamente ligadas à Unicamp.

Foram repassados a essas 64 empresas $\mathrm{R} \$ 11,2$ milhões no período, o que representa $17 \%$ dos recursos do PIPE (idem). Se dividido o montante de R \$11,2 milhões igualitariamente entre elas, cada uma teria recebido R\$ 175 mil. Nesse caso, se somadas as "filhas da Unicamp", elas teriam recebido R \$ 5,4 milhões, o que representa $48,3 \%$ dos recursos do PIPE destinados às empresas de Campinas.

IV.2. A relevância dos setores produtivos para a Universidade

Campinas destaca-se na produção de $\mathrm{C} \& \mathrm{~T}$ nacional se consideradas as estatísticas de patentes e artigos científicos produzidos por município. Apenas quatro municípios (São Paulo, Rio de Janeiro, Campinas e Joinville) detinham mais de 500 patentes entre os anos 1990 e 2000 . E apenas

\footnotetext{
3 O Programa Pesquisa Inovativa na Pequena e MicroEmpresa (PIPE) existe desde 1997 e destina-se a apoiar o desenvolvimento de pesquisas inovadoras, a serem executadas em pequenas empresas sediadas no estado de São Paulo, sobre importantes problemas em ciência e tecnologia que tenham alto potencial de retorno comercial ou social (Fapesp, 2008).

4 As empresas a que se refere o PIPE não são as mesmas
} do estudo de Souza e Garcia (1998). dois municípios (São Paulo e Rio de Janeiro) ultrapassavam, nesse período, a marca de 3000 artigos, e outros quatro (Campinas, São Carlos, Belo Horizonte e Porto Alegre) ultrapassavam a marca de 1000 artigos (ALBUQUERQUE et alii, 2001).

Entre as instituições de P\&D localizadas em Campinas, a Unicamp é que mais destaca-se na produção de patentes e artigos científicos. Todavia, apesar do destaque da Unicamp, sua importância para os setores produtivos (excetuando as empresas estatais, ao longo dos anos 1970 e 1980), enquanto transferência de tecnologia e por meio da realização de projetos de pesquisas nas empresas, tem sido modesta, como observado nos dados sobre concessão e licenciamento de patentes, nos dados do Programa de Apoio à Pesquisa em Parceria para Inovação (PITE), da Fapesp e no estudo de Brisolla et alii (1997).

Embora a transferência de tecnologia de uma instituição de $\mathrm{P} \& \mathrm{D}$ não se restrinja à produção de patentes e seus licenciamentos, este pode ser um indicador dessa atividade. De 1989 a 2006, a Unicamp solicitou o registro de 460 patentes ao Instituto Nacional da Propriedade Industrial (INPI). Nesse mesmo período foram concedidos 50 dos registros solicitados (INOVA UNICAMP, 2006).

Nos anos 2004, 2005 e 2006 a Unicamp assinou 16,28 e 30 contratos de licenciamento de patentes, respectivamente. Em 2004 havia 16 contratos de licenciamento da Unicamp com atores externos. No ano seguinte foram firmados mais 12 contratos, totalizando 28 naquele ano. Em 2006, foram firmados mais dois contratos, chegando a 30 vigentes nesse ano (idem). Esses contratos foram firmados com 24 empresas, de pequeno e médio portes, gerando uma média anual de R\$ 250 mil em royalties para a Unicamp (CASTRO, 2007), aproximadamente $0,02 \%$ da receita ${ }^{5}$ total da Universidade e $0,13 \%$ de sua receita de pesquisa $^{6}$.

Embora o número de pedidos de patentes concedidas seja igual a 50 e o de contratos de licenciamento, em 2006, igual a 30, isso não implica que mais da metade das patentes concedidas

\footnotetext{
5 A média da receita da Unicamp entre 2000 e 2007 foi de R\$ 950 milhões.

6 A média da receita de pesquisa da Unicamp entre 2000 e
} 2007 foi de R\$ 187 milhões (ver Quadro 7). 
foram licenciadas. Há contratos de licenciamento de uma mesma patente que foram firmados com mais de uma empresa (INOVA UNICAMP, 2006).

Ainda sobre indicadores de transferência de tecnologia da Unicamp para os setores privados, o PITE 7 , criado em 1995, ajuda a analisar como esse processo vem desenvolvendo-se nessa universidade. O PITE, de 1995 até 2007, co-financiou 87 projetos de pesquisa. Esses projetos foram desenvolvidos por 15 instituições de $\mathrm{P} \& \mathrm{D}$ públicas e privadas do estado de São Paulo em parceria $^{8}$ com 60 empresas, que em sua quase totalidade eram grandes empresas domésticas e estrangeiras (FAPESP, 2008). Os resultados desses projetos, como direitos sobre patentes ${ }^{9}$ e direitos de comercialização, pertencem às entidades proponentes e, em alguns dos casos, também à Fapesp (idem).

Desses 87 projetos, 35 foram desenvolvidos na USP, 15 na Unicamp, oito na Universidade Estadual Paulista Júlio de Mesquita Filho (Unesp) e os demais (29 projetos) em outras 12 instituições de $\mathrm{P} \& D$ públicas e privadas. Ou seja, do montante de projetos co-financiados pela Fapesp entre os anos 1995 e 2007, a Universidade de São Paulo (USP), a Unicamp e a Unesp foram responsáveis por $40,2 \%, 17,2 \%$ e $9,2 \%$ deles, respectivamente (idem).

Foram investidos nesses projetos $\mathrm{R} \$ 54,9 \mathrm{mi}-$ lhões. Do total de investimentos, a Fapesp foi responsável por $29 \%$ (R\$ 15,9 milhões) e as empresas pelos 70\% restantes (R $\$ 38,9$ milhões) (idem). Do total dos investimentos, a USP recebeu R $\$ 15,3$ milhões, a Unicamp, R \$ 5,1 milhões e a Unesp, R\$1,1 milhão. Divididos esses investimentos entre os anos de 1995 e 2007, a USP teria recebido

\footnotetext{
7 Programa que busca promover a interação entre instituições de P\&D e empresas, por meio da realização de projetos de pesquisa cooperativos e cofinanciados. Os projetos aprovados são contratados pela Fapesp diretamente com os pesquisadores das instituições de P\&D (FAPESP, 2008).

8 A iniciativa para o estabelecimento dessas parcerias, em $70 \%$ dos casos partiu das universidades e nos $30 \%$ restantes das empresas (MARQUES, 2008).

9 As patentes geradas por essas parcerias não são registradas pelas instituições de P\&D. Dessa forma, elas não constam da lista de patentes requeridas pelas instituições de P\&D.
}

R \$ 1,1 milhão, a Unicamp, R \$ 390 mil e a Unesp, $\mathrm{R} \$ 80$ mil por ano.

Como constatado, embora a Unicamp seja a segunda instituição de P\&D do estado de São Paulo em número de projetos financiados pelo PITE, no decorrer dos treze anos que trata o Programa, isso representou uma média de 1,15 projetos por ano desenvolvidos pelos pesquisadores dessa instituição em cooperação com as grandes empresas. Os recursos destinados a esses projetos representaram, aproximadamente, $0,04 \%$ da receita da Unicamp e $0,20 \%$ de sua receita de pesquisa.

Um estudo, concluído em 1997 por Brisolla et alii (1997), buscou contribuir para ampliar a compreensão da problemática envolvendo a interação entre universidade e empresas no Brasil, considerando, para isso, as condições estruturais das localidades em que ocorreriam essas interações. $\mathrm{O}$ estudo foi baseado em uma pesquisa realizada na Unicamp, no período de julho de 1995 a julho de 1997. A escolha da Unicamp foi devido ao seu destaque na produção de pesquisas e formação de recursos humanos qualificados no Brasil. O estudo, por meio dos indicadores "evolução dos contratos por período de tempo", "composição dos contratos segundo a categoria do financiador", "avaliação da interação, segundo os participantes" e "a aproximação entre os atores", mostra a modesta interação entre a Unicamp com os setores produtivos.

A evolução dos contratos, que compreende os anos 1981 a 1995, foi separada em três períodos de cinco anos cada, sendo que no primeiro foi somada a média aritmética dos contratos do período, para sua uniformização. Entre os períodos de 1981-1985 e 1986-1990, acompanhando a tendência de recuperação econômica promovida pelo Plano Cruzado (implementado em 1986), cresceu $240 \%$ o número de contratos da Universidade. Como resultado desse crescimento, o montante dos recursos captados elevou-se cerca de 50\% entre os períodos 1981-1985 e 1986-1990.

Esse aumento deveu-se, principalmente, aos contratos com empresas privadas. Todavia, o valor médio desses contratos foi inferior ao dos celebrados com empresas públicas ou com as agências governamentais. A diferença de composição por categoria de financiador produziu um portfólio de contratos com valores cerca de $20 \%$ inferiores entre os períodos de 1986-1990 e o anterior. 
O período 1991-1995 foi marcado por um resultado altamente negativo no que se refere ao número e ao valor médio dos contratos da Universidade. Além de ter acentuado-se (de $20 \%$ entre 1981-1985 e 1986-1990 para 43\% de redução entre 1986-1990 e 1991-1995) a queda no valor médio, verificou-se uma queda de aproximadamente $20 \%$ no número dos contratos. O volume total de recursos captados na primeira metade dos anos 1990 equivalia a $60 \%$ do valor conseguido no primeiro período analisado e a $40 \%$ do obtido no segundo período.

Quando analisada a composição dos contratos segundo a categoria do financiador, os autores verificaram que do total de 732 contratos, $27,5 \%$, foram firmados com agências de financiamento do governo, 26,6\%, com empresas privadas e
$22,4 \%$, com empresas estatais. Essas três categorias respondiam por mais de três quartos do número de projetos da Universidade. De outra perspectiva, quase $70 \%$ dos contratos foram financiados por instituições públicas (somando agências, administração pública federal, estadual e municipal).

O maior valor médio dos projetos foi financiado pelas agências governamentais, com $\mathrm{R} \$ 588 \mathrm{mil}$, aproximadamente. $\mathrm{O}$ segundo maior valor médio foi o das empresas estatais, com R $\$ 316$ mil, aproximadamente. Os contratos de menor valor foram celebrados com os institutos públicos de pesquisa, com R \$ 27 mil, em média. As empresas privadas ocuparam a penúltima posição entre as categorias de financiadores, com um valor médio de $\mathrm{R} \$ 82,5$ mil por contrato (ver Quadro 7).

\section{QUADRO 7 - FINANCIAMENTO DA P\&D NA UNICAMP (1981-1995 E 2000-2007)}

\begin{tabular}{|c|c|c|c|c|c|}
\hline $\begin{array}{l}\text { CATEGORIA DO } \\
\text { FINANCIADOR }\end{array}$ & FREQÜÊNCIA & $\begin{array}{l}\text { DURAÇÃO } \\
\text { MÉDIA }\end{array}$ & $\begin{array}{l}\text { VALOR } \\
\text { MÉDIO (R\$ }\end{array}$ & \multicolumn{2}{|c|}{$\begin{array}{c}\text { VOLUME MÉDIO DE } \\
\text { RECURSOS (R\$ MILHÕES) }\end{array}$} \\
\hline PERÍODO & \multicolumn{3}{|c|}{ 1981-1995 } & 1981-1995 & $2000-2007$ \\
\hline Agências de financiamento & 201,0 & 30,7 & 588,0 & 118,2 & 117,3 \\
\hline Empresa privada & 195,0 & 16,3 & 82,6 & 16,1 & 13,8 \\
\hline Empresa estatal & 164,0 & 21,1 & 315,9 & 51,8 & 10,3 \\
\hline Institutos públicos de P\&D & 55,0 & 13,0 & 27,2 & 1,5 & $\mathrm{~s} / \mathrm{d}$ \\
\hline $\begin{array}{l}\text { Administração pública } \\
\text { federal }\end{array}$ & 39,0 & 12,6 & 102,0 & 34,0 & 15,6 \\
\hline $\begin{array}{l}\text { Administração pública } \\
\text { estadual }\end{array}$ & 35,0 & 12,3 & 277,5 & 9,7 & 5,8 \\
\hline $\begin{array}{l}\text { Administração pública } \\
\text { municipal }\end{array}$ & 15,0 & 13,8 & 130,6 & 2,0 & 3,2 \\
\hline Instituições internacionais & 14,0 & 32,4 & 148,5 & 2,1 & 2,5 \\
\hline $\begin{array}{l}\text { Universidades e ONGs } \\
\text { nacionais }\end{array}$ & 14,0 & 17,4 & 180,0 & 2,5 & $s / d$ \\
\hline Financiamento próprio & $\mathrm{s} / \mathrm{d}$ & $s / d$ & $\mathrm{~s} / \mathrm{d}$ & $s / d$ & 2,5 \\
\hline Fundos de C\&T & $\mathrm{s} / \mathrm{d}$ & $\mathrm{s} / \mathrm{d}$ & $\mathrm{s} / \mathrm{d}$ & $s / d$ & 16,2 \\
\hline TOTAIS & 732,0 & 21,0 & 325,0 & 237,9 & 187,2 \\
\hline
\end{tabular}

FONTES: os autores, a partir de Brisolla et alii (1997) para 1981-1995 e Unicamp (2007) para 2000-2007.

NOTAS: 1 . O volume médio de recursos no período 2000-2007 foi calculado com base nos recursos alocados em P\&D na Unicamp.

2. ONGs: organizações não-governamentais.

3. s/d: sem dados.

A duração média dos contratos foi maior com as instituições internacionais, com média de 32,5 meses de duração. Porém, quando considerados os recursos financeiros, esses convênios foram bastante modestos. Eles referiam-se, geralmente, ao apoio institucional de pequena monta, como a 
compra de material de consumo de laboratórios, bolsas de estudos e outras atividades que, por sua natureza, desenvolvem-se por períodos mais longos.

As agências de financiamento (principalmente a Financiadora de Estudos e Projetos (Finep)) contrataram projetos por um período médio de 30,7 meses, e as empresas estatais, por 21 meses em média, que são períodos bastante elevados. Os contratos com empresas privadas duraram, em média, 16 meses.

As agências de financiamento foram responsáveis, no período de 1981-1995, por um montante de $\mathrm{R} \$ 118$ milhões destinados à Universidade, o que corresponde a $50 \%$ dos recursos extraorçamentários que entraram na Unicamp. No segundo período analisado elas continuaram sendo os maiores financiadores da $\mathrm{P} \& \mathrm{D}$ da Unicamp, tendo inclusive sua participação elevado-se para $63 \%$ do total de recursos.

Excetuando-se as agências de financiamento, foram as empresas estatais, no período 1981-1995, que mais contribuíram para o financiamento da $P \& D$ da Universidade. Isso se expressa no volume total de recursos, segundo a categoria do financiador. Porém, no período de 2000-2007 verifica-se uma significativa redução do volume de recursos destinados à $\mathrm{P} \& \mathrm{D}$ na Unicamp pelas empresas estatais. No primeiro período, as empresas estatais respondiam por $21 \%$ do financiamento da P\&D da Unicamp. Já no segundo período, sua participação foi reduzida a 5,5\% do total de recursos de financiamento à $\mathrm{P} \& \mathrm{D}$ da Universidade.

A administração pública federal também teve importância de destaque no financiamento à $P \& D$ da Unicamp no primeiro período analisado. Nele, a administração pública federal foi responsável por $14 \%$ do total de financiamento. Porém, no segundo período sua participação foi igual a $8 \%$ do total de financiamento. No período de 1981 a 1995, as empresas privadas representavam $26,6 \%$ do número de contratos da Universidade, porém somavam apenas $6,8 \%$ do volume médio de recursos. No segundo período sua participação não sofreu grande alteração, pois ela foi elevada para 7,3\% do financiamento à $\mathrm{P} \& \mathrm{D}$ da Unicamp. Mesmo a participação das empresas privadas, em termos relativos ter se elevado; em termos absolutos ela teve uma queda de $15 \%$ (2,3 milhões de reais a menos destinados ao financiamento à $\mathrm{P} \& \mathrm{D}$ da
Unicamp) no período de 2000 a 2007, em relação ao anterior.

Se somados os financiamentos públicos ${ }^{10}$, eles representavam no primeiro período $92 \%$ do total da P\&D da Unicamp. No segundo período eles representavam $93 \%$ do total do financiamento à P\&D da Unicamp. Outro dado importante, que pode ser visto no Quadro 7, é que houve redução no financiamento à $P \& D$ da Unicamp entre os dois períodos. Essa redução deve-se em maior medida à queda na participação das empresas estatais, que foi de $80 \%$ entre os dois períodos, o que representou 41 milhões de reais a menos no financiamento à $\mathrm{P} \& \mathrm{D}$ da Unicamp.

Sobre a categoria avaliação da interação, segundo Brisolla et alii (1997), a grande maioria dos contratos realizados com o setor produtivo estava voltada à pesquisa e desenvolvimento (68\%), sendo que $41 \%$ foram projetos de desenvolvimento, $14 \%$, de pesquisa e $13 \%$, de cunho exclusivamente tecnológico. Atividades de prestação de serviços corresponderam a $19 \%$, e cursos e treinamentos responderam por apenas $6 \%$ dos contratos. Contratos envolvendo consultorias e assessorias, projetos de engenharia, análises de rotina, informações técnico-científicas, como um todo, representaram apenas $5 \%$. Cerca de $60 \%$ dos contratos tiveram relações de cooperação envolvendo membros da entidade financiadora $\mathrm{e}$ equipes de pesquisadores. Isso foi especialmente verdadeiro para os contratos de $\mathrm{P} \& \mathrm{D}$, embora nas prestações de serviço, nas quais era esperada uma baixa interação entre as equipes, relações de cooperação foram também significativas.

Quanto à aproximação entre os atores, os motivos que levaram os pesquisadores a interagirem com o setor empresarial foram a busca de recursos financeiros e a identificação de temas de pesquisa. É interessante notar que a informalidade marcou os contatos iniciais. Em mais de $50 \%$ dos contratos estudados, os contatos pessoais informais foram a principal via de acesso utilizada pelos atores. Ex-alunos, participação em congressos, organização de workshops, foram mencionados como situações que favore-

10 Agências de financiamento, empresas estatais, institutos públicos de $\mathrm{P} \& \mathrm{D}$, administração pública federal, administração pública estadual, administração pública municipal, financiamento próprio e fundos de C\&T. 
ceram o estabelecimento de contatos, não apenas de iniciativa das empresas, mas também de membros da comunidade de pesquisa. Ao passo que, ao longo dos anos 1980 e 1990, foi bastante tímido o desempenho das instituições de enlace ${ }^{11}$ entre a Unicamp e os setores produtivos privados.

Apesar de ter um grande destaque quanto à produção de C\&T no Brasil, isso se forem considerados os indicadores apresentados acima, a relação da Unicamp com os setores produtivos tem sido bastante modesta em termos de transferência de tecnologia para os setores produtivos. Essa instituição vem produzindo C\&T, que, no limite, não tem relevância para esses setores.

\section{IV.3. O porquê dos resultados da política do PATC}

Sobretudo no Brasil, é muito comum atribuirse a déficits de implementação a causa do insucesso de determinadas políticas públicas. É freqüente a afirmação de que "o Brasil, nessa área, possui a política mais avançada do mundo. Todavia, sua implementação tem sido muito difícil". Para entender-se o porquê disso, o EAn remete o analista de políticas aos momentos anteriores à implementação. Embora o insucesso da política somente materialize-se quando ela é implementada, as razões que o explicam remetem ao momento da tomada de decisão, formulação e mesmo da construção do problema público.

A utilização desse Enfoque no estudo da política pública do PATC $^{12}$ permitiu evidenciar dois de seus aspectos fundamentais, pertinentes aos momentos anteriores à implementação dessa Política, que ajudam a entender o porquê dos seus modestos resultados depois de passados mais de trinta anos do início do processo de sua elaboração. $\mathrm{O}$ primeiro aspecto é a emulação das experiências de PATs (Pólos e Parques de Alta Tecnologia) dos países de capitalismo avançado, o qual está relacionado com a concepção que a comunidade de pesquisa, e mesmo a sociedade de forma geral, possui acerca da C\&T. O segundo é a política pública constituir-se como uma política simbóli-

\footnotetext{
11 São elas: para o Desenvolvimento Tecnológico (Codetec), o Centro de Tecnologia (CT), o Centro de Incentivo à Parceria Empresarial (CIPE) e o Escritório de Transferência de Tecnologia (ETT).

12 Um estudo mais detalhado do processo de elaboração da política pública do PATC pode ser encontrado em Silva (2008).
}

ca, o qual está relacionado com as especificidades da sociedade em que a política foi formulada e que impedem que ela seja implementada.

O fenômeno da emulação, ou geração de mecanismos de interface que tentam imitar as experiências de sucesso dos países de capitalismo avançado (THOMAS et alii, 1997), não se restringe à política do PATC. Ele perpassa as diversas propostas de arranjos institucionais elaboradas no Brasil e, em geral, as políticas que buscam estimular a interação entre universidade e empresa. Os argumentos da comunidade de pesquisa, de que a debilidade da interação entre o potencial de C\&T e o desenvolvimento econômico era um problema grave nos países de capitalismo periférico e que ele deveria ser enfrentado, foram aceitos pelos fazedores de política.

Ainda que não houvesse um consenso entre os membros da comunidade de pesquisa sobre as causas e possíveis soluções desse problema, a alternativa efetivamente aceita, a qual continua vigente até hoje, para a resolução do problema foi a que buscava fazer com que o potencial de C\&T fosse utilizado pelo sistema produtivo. A alternativa partiu da concepção de membros da comunidade de pesquisa de que as demandas por conhecimento - seja ele incorporado em pessoas ou desincorporado - poderiam, tal como observado nos países de capitalismo avançado, ser reduzidas àquelas exercidas pelas empresas. Nessa alternativa, as empresa constituíram-se em um pólo a ser conectado. O outro pólo, cuja função seria produzir conhecimento, e que para isso contava com o apoio do Estado, seriam as universidades (DAGNINO, 2004).

Essa concepção da comunidade de pesquisa brasileira tem sua base no modelo ofertista linear. Esse modelo surgiu nos países de capitalismo avançado, inicialmente nos Estados Unidos, depois que a comunidade científica "ganhou a guerra" contra o fascismo, com o projeto Manhattan e a bomba atômica. Nesse período é quando se estabelece um novo contrato social entre a comunidade de pesquisa e o Estado. Esse contrato garantiria que a sociedade pudesse ser sempre beneficiada pelos frutos do conhecimento custeado pelo Estado e que, em retribuição, seriam oferecidos pelos "homens de ciência" (DAGNINO, 2002).

Vários autores vêm mostrando como esse modelo foi gerado e transplantado para os países de capitalismo periférico, incluindo o Brasil. A sis- 
tematização de suas cinco idéias-força busca destacar por que esse modelo segue orientando as proposições da comunidade de pesquisa latinoamericana. A primeira idéia é a de que a ciência, por ser neutra (inerentemente boa e desprovida de valores sociais), deveria ser apoiada pelo Estado em nome da sociedade. Ela estava latente no caldo de cultura do Iluminismo e do positivismo. Por integrar o "senso comum" legitimador do capitalismo, fortaleceu-se com ele (idem). A segunda surge da perspectiva empírica do pesquisador (de seu laboratório) no processo de inovação. Ele via como à pesquisa básica sucedia-se a pesquisa aplicada e, a esta, o desenvolvimento tecnológico permitia o lançamento de um novo produto que poderia gerar um benefício econômico e, finalmente, social. De forma reducionista, os pesquisadores assimilaram esse evento contido e controlado, que ocorria no nível "micro" (em particular no interior de laboratórios de empresas ou a ela mais diretamente ligados) e outro, exterior, que se dava no nível "macro" dos processos sociais, sujeitos a determinantes muito mais complexos e pouco controláveis. Algo semelhante àquilo que em Biologia conhece-se como o mecanismo de ilação ontogenia-filogenia, que serviu de legitimação ao modelo descritivo da "cadeia linear de inovação". Apoiado na credibilidade dos cientistas, ele transformou-se no modelo normativo da política de C\&T (idem).

A terceira idéia, de massa crítica, que passou a integrar o repertório da comunidade de pesquisa com o projeto Manhattan, potencializou as anteriores. Ela argumentava que seria a concentração, até chegar a uma massa crítica, do elemento pesquisa básica e dos recursos humanos na sociedade que seriam oferecidos pela comunidade de pesquisa mediante o apoio do Estado, o que desencadearia a reação da cadeia linear de inovação de forma auto-sustentada (idem). A quarta idéia parte do entendimento da pesquisa básica como o detonador do processo de inovação. Ela justificava a concessão pelo Estado dos meios que necessitava a comunidade de pesquisa para materializar a promessa da cadeia linear. Porém, ela ia além ao atribuir a essa comunidade o papel central na elaboração da política pública com a qual estava envolvida (idem).

A quinta idéia é a de modernidade. Baseada na visão eurocêntrica, que a considerava uma conseqüência da capacidade dos países de gerar e absorver progresso técnico, ela ganha força no Pós Segunda Guerra Mundial. Um corolário dessa idéia é que se a sociedade mostra-se incapaz de absorver o conhecimento que a comunidade de pesquisa oferece é porque ela encontra-se em um estágio atrasado. O que implicaria na necessidade de aumentar ainda mais a oferta de ciência (e o apoio que recebia a comunidade de pesquisa) de modo a fazer com que, via modernização, a sociedade viesse a valorizar e demandar mais ciência. Esse argumento "quase tautológico" embute um gatilho no modelo que dispararia sempre a favor do aumento do apoio à ciência (idem).

Nos países de capitalismo avançado, há uma teia de relações sociais formada por empresas, Estado e sociedade em geral, para os quais o conhecimento gerado a partir desse modelo é funcional. Essa teia vai evidenciando, vai sinalizando, ao longo do tempo, os campos de conhecimento que são mais relevantes para aquela sociedade. Campos de relevância que podem ser entendidos como a resultante dos projetos que seus atores dominantes - as elites econômicas e políticas apontam enquanto demanda por conhecimento que deve ser gerado pela comunidade de pesquisa (idem).

Esses "sinais" de relevância, em geral difusamente "emitidos", são "captados" pela comunidade de pesquisa, que "decodifica" esses "sinais" a partir de modelos descritivos, normativos e institucionais, preconceitos, mitos e "verdades de sentido comum". Esses sinais vão conformando o caldo de cultura da pesquisa por meio do qual o sinal de relevância (substantivo e ex-ante) é "decodificado" pela comunidade de pesquisa que leva à construção de um sinal de qualidade (adjetivo e ex-post). E é esse sinal que, finalmente, pode ser processado e operacionalizado mediante a formação do critério de qualidade e do juízo dos pares, que orientam a ação da comunidade de pesquisa dos países de capitalismo avançado. O resultado é um mecanismo que reduz o compromisso social da comunidade de pesquisa a uma mera garantia de qualidade da pesquisa que vai ser feita com o dinheiro público, uma vez que a relevância está "garantida" pela teia social de atores (idem).

Os conceitos de teia de relações e de campo de relevância, que no caso dos países de capitalismo avançado aparecem como evidentes, permitem perceber o efeito do modelo ofertista linear 
na América Latina. Em particular, porque a comunidade de pesquisa latino-americana considera que qualidade em pesquisa - um conceito que nos países de capitalismo avançado depreende-se daqueles dois outros - é não apenas neutra, anistórica e universal, mas, vale a redundância, a única possível (idem). São poucos os que se dão conta de que o conceito de qualidade que a comunidade de pesquisa brasileira adota é, na realidade, histórica e socialmente construído nos países de capitalismo avançado. Isso é, que "pertence" a outro campo de relevância estabelecido por outra teia de relações. Por ser datado e formado no interior de outro contexto econômico, social e político, esse conceito é funcional aos interesses dos atores sociais que nele manifestam-se de forma hegemônica (idem).

Devido à concepção que os atores sociais (incluindo a comunidade de pesquisa) possuem acerca da C\&T - de que ela é neutra -, tornou-se amplamente aceito que a comunidade de pesquisa deva ser o ator dominante na elaboração da PCT (DAGNINO, 2007). Política essa, que por ser percebida pelos atores como policy e não como politics segue, tal como o modelo de C\&T dos países de capitalismo avançado, sendo emulada pelos países de capitalismo periférico. A proposta que se tornou relativamente freqüente entre os atores dominantes no processo de elaboração da PCT diz respeito ao estímulo à formação de PATs, com o intuito de criar um ambiente institucional favorável ao surgimento de inovações tecnológicas tal como nos países de capitalismo avançado (DAGNINO, 2002).

A prática da importação de modelos constitui um processo comum entre os países de capitalismo avançado. Entre eles essa prática não se mostra muito problemática, uma vez que suas características estruturais não apresentam disparidades muito relevantes (DIAS, 2005). No caso da emulação de experiências realizadas no contexto dos países de capitalismo avançado por um país de capitalismo periférico, como o Brasil, devido às discrepâncias estruturais existentes entre esses dois conjuntos de países, essa prática pode gerar graves conseqüências. Além da emulação de arranjos institucionais dos países de capitalismo avançado, outro aspecto que ajuda a compreender o porquê dos modestos resultados do PATC diz respeito a ele ter constituído-se como uma política simbólica.
A emulação dos PATs como proposta de política pública, tal como ocorreu no caso do PATC, implicava que os tomadores de decisão, além de conceberem a C\&T como neutra e universal, acreditarem que três elementos, que se supunha permitir o desenvolvimento dessas experiências nos países de capitalismo avançado, estivessem presentes no Brasil e, invariavelmente, em Campinas. São eles: i) ator empresa altamente demandante de P\&D, desenvolvida localmente, como elemento central de sua competitividade; ii) $o$ ator universidade formador dos pesquisadores que desenvolveriam P\&D nas empresas; iii) o ator Estado com o poder de articular e coordenar os atores empresa e universidade com vistas à inovação tecnológica.

Sobre o primeiro elemento - ator empresa altamente demandante de inovações tecnológicas -, uma olhada mais atenta para a realidade brasileira, e conseqüentemente na de Campinas, mostraria que o ator econômico que aqui é chamado de empresa não é exatamente o que nos países de capitalismo avançado recebe esse nome. Isso é, não cumpre as mesmas funções. Ao adotar acriticamente o marco de referência gerado nesses países para tratar sua realidade, a comunidade de pesquisa brasileira incorreu no "pecado epistemológico" de chamar pelo mesmo nome (usar o mesmo significante: empresa) coisas com significados diferentes (DAGNINO, 2004).

Nos países de capitalismo avançado, as empresas (as grandes empresas) nacionais é que controlavam a inovação, tanto com a produção de novos produtos quanto de processos, dentro de suas economias. Essas empresas também eram as responsáveis por grande parte das transações internacionais e detinham a iniciativa nesse terreno (FURTADO, 1974). Como destacado por Furtado (1972), as empresas localizadas no Brasil não atuavam da mesma forma. Segundo esse autor, no país existiriam três categorias de empresas: um setor privado nacional formado por um limitado número de grandes firmas que sobreviviam com maior ou menor grau de autonomia e por um número considerável de pequenos empresários; um poderoso setor privado estrangeiro, orientado por dirigentes estrangeiros ou brasileiros, formado por filiais ou empresas subsidiárias de consórcios internacionais; outro setor de importância crescente que era formado pelas empresas públicas, quase sempre originárias da administração civil ou militar. 
As atividades dirigidas por esses três grupos tendiam a ser mais complementares do que competitivas. As empresas controladas diretamente pelo Estado tinham a exclusividade de certas áreas. Elas dominavam as atividades infra-estruturais ou criadoras de economias externas, as quais requeriam grandes imobilizações de capital e não eram afetadas pelo progresso técnico (inovações tecnológicas) (idem). O grupo privado nacional controlava as atividades de construção e certas manufaturas tradicionais. Ele também operava como sub-contratista das empresas estatais e das estrangeiras. O grupo das empresas estrangeiras tinha o controle quase que absoluto das indústrias de bens de consumo duráveis, químico-farmacêuticas e de equipamentos em geral, que em conjunto eram as que mais expandiam-se e as que mais inseriam o progresso técnico na sua produção (idem).

O dinamismo econômico dos países de capitalismo avançado decorria do fluxo de inovações tecnológicas e da elevação dos salários reais da população, o que lhes permitia a expansão do consumo de massa. No Brasil, todavia, o dinamismo econômico desenvolvia-se com base em um mimetismo cultural e na permanente concentração de renda, o que fazia com que uma minoria da população pudesse reproduzir o padrão de consumo dos países de capitalismo avançado enquanto a grande maioria estava vivendo na pobreza (FURTADO, 1974). Dado a isso, as empresas brasileiras voltavam sua produção para atender à progressiva satisfação do consumo dessa minoria com poder de consumo. Como o processo de diferenciação e criação de novos produtos apoiava-se, do lado da demanda, na adoção dos hábitos de consumo dos países de capitalismo avançado, as empresas brasileiras (estrangeiras e domésticas) utilizavam tecnologias transferidas do exterior para produzi-los. Nesse caso, a inovação constituía-se apenas em produzir internamente o bem já fabricado nos países de capitalismo avançado (BIATO, GUIMARÃES \& FIGUEIREDO, 1973).

Outro fator que diferenciaria as empresas, ou melhor, as economias, dos países de capitalismo avançado das empresas dos países de capitalismo periférico seria a retenção pelos primeiros dos frutos do progresso técnico. A diminuição da oferta de mão-de-obra nos países de capitalismo avançado elevaria o valor da remuneração salarial. Em resposta a isso, os capitalistas (empresários) desses países tenderiam a desenvolver inovações tecnológicas poupadoras de mão-de-obra, mas capazes de manter a taxa de lucro com a obtenção de mais-valia relativa (Furtado apud CEPÊDA, 2008). Nos países de capitalismo periférico, devido a sua grande oferta de mão-de-obra, as empresas não percorreriam o mesmo caminho dos países de capitalismo avançado. Por não sofrerem pressão salarial, não necessitariam de renovações tecnológicas. Sua taxa de lucro seria mantida por meio da extração de mais-valia absoluta com a redução dos salários (idem).

Mesmo na atualidade, as estratégias de inovação das empresas brasileiras não estão baseadas no investimento em P\&D. Suas estratégias continuam baseadas na transferência de tecnologia e não no desenvolvimento de $\mathrm{P} \& \mathrm{D}$ interno a elas. Segundo dados da Pintec (IBGE, 2005), em 2005, 32800 empresas brasileiras fizeram inovação tecnológica em produto ou processo. Desse total, 30377 são industriais e 2418 são prestadoras de serviços de alta tecnologia (nos setores de telecomunicações, informática e pesquisa e desenvolvimento). Do total de empresas que inovaram, $20 \%$ (6 560 empresas) fizeram isso por meio de investimento de parte de sua receita em P\&D. Ao passo que $48,4 \%$ (15 875 empresas) inovaram por meio da aquisição de máquinas e equipamentos.

Caso some-se as demais modalidades de inovação (aquisição externa de $\mathrm{P} \& \mathrm{D}$; outros conhecimentos externos; introdução de inovação tecnológica já existente no mercado; projeto industrial; treinamento), que juntos correspondem a $31,4 \%$ das atividades de inovação, com a aquisição de máquinas e equipamentos, o percentual de inovação das empresas feito por meio da aquisição de produtos ou processos já existentes no mercado seria igual a $80 \%$ (IBGE, 2005). Sobre o segundo elemento $-\mathrm{o}$ ator universidade formador dos pesquisadores que desenvolveriam $\mathrm{P} \& \mathrm{D}$ nas empresas -, a comunidade de pesquisa brasileira concebia que, tal como nos países de capitalismo avançado, o lugar da ciência e da educação seria a universidade e o lugar do desenvolvimento ou da demanda de tecnologia, seria a empresa. O elemento criador de inovação seria o cientista ou engenheiro trabalhando em atividades de $\mathrm{P} \& \mathrm{D}$ nas empresas (BRITO CRUZ, 2002).

Todavia, uma análise mais crítica sobre a estrutura produtiva brasileira mostraria que, distinto do que se observava nos países de capitalismo avançado, as universidades não viriam a desem- 
penhar um papel fundamental nela. Elas, diferentemente do que se pretendia, não seriam formadoras dos cientistas e engenheiros e, também, não geriam as inovações tecnológicas demandadas pelas empresas brasileiras. As empresas brasileiras eram (e continuam sendo), em sua maioria, filiais de firmas estrangeiras, que possuem seus próprios programas de lucro e investimentos. Por isso mesmo, a influência de tais empresas no desenvolvimento da C\&T no Brasil tem sido praticamente nula. Na verdade, essas corporações possuem laboratórios próprios de pesquisa, em seus países de origem (LEITE LOPES, 1981).

Por sua vez, as empresas domésticas utilizam conhecimento científico e tecnológico provenientes dos países de capitalismo avançado (idem). Uma vez que a demanda da sociedade brasileira (aquela minoria que pode consumir) por novos produtos ou processos reproduz o padrão de consumo dos países de capitalismo avançado, ela é satisfeita com transferência de tecnologias importadas. Ou seja, para atender a essa demanda, as empresas domésticas não necessitariam investir em P\&D. Admitindo que a comunidade de pesquisa aconselhasse o governo brasileiro a adotar uma política de manutenção e estímulo às universidades, à pesquisa científica e à cultura, paralelamente a um indispensável programa intensivo de educação básica, ainda permaneceria uma dificuldade fundamental. A saber: a utilização (a colocação) dos cientistas (pesquisadores) pelas empresas brasileiras (idem).

Se essas empresas estavam operando com base nos trabalhos científicos e tecnológicos realizados no exterior, tornava-se claro que os pesquisadores formados pelas universidades locais não teriam muita oportunidade de emprego em hipotéticos laboratórios de pesquisa dessas corporações (estrangeiras ou domésticas). As empresas não estavam, portanto, interessadas em estabelecer vínculos com os laboratórios e universidades brasileiras (idem). Mesmo hoje permanece baixa a importância da interação das empresas com outras instituições, em especial com as universidades, como estratégia de inovação tecnológica. Segundo dados da Pintec (IBGE, 2005), a cooperação com outras organizações no desenvolvimento de atividades inovadoras foi pouco utilizada pelas empresas brasileiras (RAPINI, 2007).

Do conjunto das firmas inovadoras (aquele universo de 32800 empresas), somente $11 \%$ valeram-se da estratégia de interagir com outras organizações como meio de desenvolver inovações. Em termos de parceiros, a maior proporção de relações de cooperação ocorreu com fornecedores e clientes $(6 \%$ e $5 \%$, respectivamente) das empresas inovadoras, e apenas 3,7\% com universidades (idem). Sobre o terceiro elemento - o ator Estado com o poder de articular e coordenar os atores empresa e universidade com vistas à inovação tecnológica -, pretendia-se que o Estado brasileiro adotasse o mesmo modelo dos países de capitalismo avançado. Ou seja, um Estado responsável por administrar as regras de interação entre os atores, regulamentar as informações a que eles poderiam ter acesso e orientar seus comportamentos para promover o desenvolvimento industrial baseado na inovação tecnológica (CIMOLI et alii, 2007).

Todavia, uma olhada mais atenta sobre a política industrial brasileira mostraria o quão distante ela estava, já na década de 1970, de uma coordenação nacional. Como apontado por Furtado (1974), o dado mais importante a assinalar, no que concernia aos países de capitalismo periférico em mais avançado processo de industrialização, era a considerável difículdade de coordenação de suas economias no plano interno. Isso acontecia devido à forma como vinham sendo articuladas as economias nacional e internacional, esta fortemente influenciada pelas grandes empresas. A debilidade do Estado enquanto instrumento de direção e coordenação das atividades econômicas, em função de algo que se possa definir como interesse da coletividade local, passou a ser um fator significativo no seu processo de desenvolvimento (idem).

Outro ponto importante que impossibilitaria a coordenação do Estado sobre os atores e as atividades de inovação era a correlação de forças políticas na sociedade brasileira. A correlação de forças políticas, que sancionou uma crescente e brutal concentração de poder econômico, muito pouco espaço deixaria para que o conhecimento e os recursos humanos qualificados, que o complexo de $\mathrm{C} \& \mathrm{~T}$ poderia produzir, pudessem ser utilizados para o desenvolvimento de inovações tecnológicas (DAGNINO \& THOMAS, 1999).

Esses três elementos seriam suficientes para apontar que as propostas de solução para o problema público, definidas no momento da formulação, não levariam à sua resolução. Os 
formuladores das propostas de emular as experiências norte-americanas de Pólos e Parques de Alta Tecnologia (anos 1970 e 1980) e vincular os setores produtivos ao desenvolvimento da C\&T, tendo como centrais as empresas de alta tecnologia (anos 1990 em diante), não consideraram essas especificidades da sociedade brasileira.

\section{CONSIDERAÇÕES FINAIS}

O Enfoque de Análise de Políticas (EAn) não focaliza apenas o momento da implementação da política e os resultados dele advindos. O EAn foca sua análise também nos demais momentos do processo de elaboração das políticas. No EAn, a política pública deve ser entendida como um curso de ação, que envolve a definição de metas e objetivos e, principalmente, das diretrizes que devem permitir que eles sejam logrados, escolhido por autoridades públicas para focalizar um problema público. É importante destacar que, em alguns casos, as políticas públicas também podem envolver cursos de inação, o que caracteriza um processo de não tomada de decisão, em que o governo não tem intenção propriamente de resolver um problema público.

O EAn permite a análise do contexto político e ideológico e as relações de poder existentes entre os atores envolvidos e atingidos por uma dada política, assim como do modelo cognitivo empregado em sua formulação. Por meio dele, evidenciam-se os elementos de caráter político-ideológico atinentes aos atores, às redes que eles conformam e aos ambientes em que se verificam as atividades abarcadas pela política. Para que isso seja feito, $\mathrm{o}$ analista de políticas deve recorrer às idéias de uma série de disciplinas diferentes a fim de interpretar a política e as relações que a con- formam. Se considerada a política pública como um curso de ação, que envolve definições de metas, objetivos e, principalmente, de diretrizes para focalizar um problema público (HAM \& HILL, 1993; ROTH, 2006; CAVALCANTI, 2007), a política do PATC não poderia, de modo estrito, ser consideradas como tal.

A política do PATC corresponde a uma politica simbólica. Por ter sido formulada para emular as experiências de PATs dos países de capitalismo avançado, não encontrou aqui as mesmas condições sociais que permitiam o desenvolvimento dos PATs nos países de origem. Formulação que está relacionado com a concepção que a comunidade de pesquisa e os policy makers (e mesmo a sociedade de forma geral) possuem acerca da C\&T fundada na idéia de neutralidade.

Após quase três décadas do início da política do PATC, seus resultados têm sido bastante modestos. Os apontamentos críticos de autores dos países de capitalismo avançado acerca dos PATs - de que a formação e estreitamento da relação universidade-empresa não demandavam proximidade física; de que a criação de infra-estrutura não era condição suficiente para promover uma eficiente rede de comunicação e relacionamento; de que a criação de empresas, atribuída à vinculação com as universidades, apresentava-se mais como exceção do que como regra; de que as empresas de alta tecnologia não tenderiam a deixar os PATs para transformarem-se em unidades produtivas e que não demandariam significativamente mão-de-obra especializada; de que as empresas de grande porte não eram propensas a relacionarem-se com as universidades (GOMES, 2001) - não foram levados em conta na formulação do PATC.

Rogério Bezerra Silva (rogerio.silva@ige.unicamp.br) é Mestre e Doutorando em Política Científica e Tecnológica pela Universidade Estadual de Campinas (Unicamp).

Renato Dagnino (rdagnino@ige.unicamp.br) é Professor Titular do Departamento de Política Científica e Tecnológica da Universidade Estadual de Campinas (Unicamp).

\section{REFERÊNCIAS BIBLIOGRÁFICAS}

ALBUQUERQUE，E. M.; SIMÕES，R.; BAESSA, A.; CAMPOLINA, B. \& SILVA, L. 2001. A distribuição espacial da produção cientifica e tecnológica brasileira: uma des- crição de estatísticas de produção local de patentes e artigos científicos. Artigo apresentado no XXIX Encontro Anual da Associação Nacional dos Centros de Pós-Graduação em 
Economia, realizado em Salvador, de 11 a 14 de dezembro. Disponível em: http://www. anpec.org.br/encontro2001/artigos/ 200105365.pdf. Acesso em: 15.set.2011.

BIATO, F. A; GUIMARÃES, E. A. \& FIGUEIREDO, M. H. 1973. A transferência de tecnologia no Brasil. Brasília: Instituto de Pesquisa Econômica Aplicada.

BRISOLLA, S.; CORDER, S.; GOMES, E. \& MELLO, D. 1997. As relações universidadeempresa-governo: um estudo sobre a Universidade Estadual de Campinas. Educação e Sociedade, Campinas, ano XVIII, n. 61, v. 18, p. 187-209, dez. Disponível em: http:// www.scielo.br/pdf/es/v18n61/4704.pdf. Acesso em: 15.ago.2011.

BRITO CRUZ, C. H. 2002. A Universidade, a empresa e a pesquisa que o país precisa. In: SANTOS, L. W.; ICHIKAWA, E. Y.; SENDIN, P. V. \& CARGANO, D. F. (orgs.). Ciência, tecnologia e sociedade: o desafio da interação. Londrina: Instituto Agronômico do Paraná.

2005. Física e indústria no Brasil. Ciência e Cultura, São Paulo, v. 57, n. 3, p. 47-50, jul.-set. Disponível em: http://cienciaecultura. bvs.br/pdf/cic/v57n3/a21v57n3.pdf. Acesso em: 15.set.2011.

CASTRO, F. 2007. Primeira em patentes. Agência Fapesp, São Paulo, 27.dez. Disponível em: http://agencia.fapesp.br/8217. Acesso em: 15.set.2011.

CAVALCANTI, P. A. 2007. Sistematizando e comparando os enfoques de avaliação e análise de políticas públicas: uma contribuição para a área educacional. Campinas. Tese (Doutorado em Educação). Universidade Estadual de Campinas. Disponível em: http://cutter.unicamp.br/ document/?code $=$ vtls000422928. Acesso em: 15.set.2011.

CEPÊDA, V. A. 2008. Celso Furtado e a interpretação do subdesenvolvimento. In: LIMA, M. C. \& DAVID, M. D. (orgs.). A atualidade do pensamento de Celso Furtado. São Paulo: Verbena.

CIMOLI, M.; DOSI, G.; NELSON, R. \& STIGLITZ, J. 2007. Instituições e políticas moldando o desenvolvimento industrial: uma nota introdutória. Revista Brasileira de Inovação, Rio de Janeiro, v. 6, n. 1, p. 55-85, jan.-jun. Disponível em: http://www.ige. unicamp.br/ojs/index.php/rbi/article/view/314/ 233 . Acesso em: 15.set.2011.

COSTA, I. 2003. Empresas multinacionais e capacitação tecnológica na indústria brasileira. Campinas. Tese (Doutorado em Política Científica e Tecnológica). Universidade Estadual de Campinas. Disponível em: http:// cutter.unicamp.br/document $/$ ? code $=$ vtls000295270. Acesso em: 15.set.2011.

DAGNINO, R. 2002. A relação pesquisa-produção: em busca de um enfoque alternativo. Revista Iberoamerica de Ciencia, Tecnología, Sociedad e Innovación, Madrid, n. 3, mayoago. Disponível em: http://www.oei.es/ revistactsi/numero3/art01.htm\#. Acesso em: 15.set.2011.

2004. C\&T no nível local: uma proposta de esquerda. Revista Espacios, Caracas, v. 25, n. 3. Disponível em: http://www.revista espacios.com/a04v25n03/04250331.html. Acesso em: 15.set.2011.

2007. Os modelos cognitivos das políticas de interação universidade-empresa. Convergência, Toluca, v. 14, n. 45, p. 95-110, sept.-dec. Disponível em: http://redalyc. uaemex.mx/pdf/105/10504505.pdf. Acesso em: 15.set.2011.

DAGNINO, R. \& THOMAS, H. 1999. Insumos para um planejamento de C\&T alternativo. Revista Planejamento e Politicas Públicas, Brasília, n. 20, dez.

DIAS, R. B. 2005. A politica científica e tecnológica latino-americana: relações entre enfoques teóricos e projetos políticos. Campinas. Dissertação (Mestrado em Política Científica e Tecnológica). Universidade Estadual de Campinas. Disponível em: http://cutter. unicamp.br/document/?code=vtls000375362. Acesso em: 15.set.2011.

DIAS, R. B. \& DAGNINO, R. 2006. A politica científica e tecnológica brasileira: três enfoques teóricos, três projetos políticos. Anais das VI Jornadas Latinoamericanas de Estudios Sociales de la Ciencia y la Tecnologia, realizadas em Bogotá (Colômbia), de 19 a 21 de abril. Disponível em: http://www.ige.unicamp.br/ gapi/TRES_ENFOQUES_TRES_PROJETOS_ POLITICOS.pdf. Acesso em: 15.set.2011. 
FREY, K. 2000. Políticas públicas: um debate conceitual e reflexões referentes à prática da análise de políticas públicas no Brasil. Planejamento e Políticas Públicas, Rio de Janeiro, n. 21, p. 211-259. Disponível em: http:// www.ipea.gov.br/ppp/index.php/PPP/article/ viewFile/89/158. Acesso em: 15.set.2011.

FURTADO, A.; QUADROS, R. \& DOMINGUES, S. 2007. Intensidade de P\&D das empresas brasileiras. Inovação Uniemp, Campinas, v. 3, n. 6, p. 26-27, dez. Disponível em: http://inovacao.scielo.br/pdf/inov/v3n6/ a13v3n6.pdf. Acesso em: 15.set.2011.

FURTADO, C. 1972. Análise do "modelo" brasileiro. $3^{\mathrm{a}}$ ed. Rio de Janeiro: Civilização Brasileira.

1974. O mito do desenvolvimento econômico. Rio de Janeiro: Paz e Terra.

GOMES, E. J. 2001. A relação universidade-empresa no Brasil: testando hipóteses a partir do caso da Unicamp. Campinas. Tese (Doutorado em Política Científica e Tecnológica). Universidade Estadual de Campinas. Disponível em: http://cutter.unicamp.br/document/ ? $\operatorname{code}=$ vtls000231879. Acesso em: 15.set.2011.

HAM, C. \& HILL, M. 1993. The Policy Process in the Modern Capitalist State. London: Harvester.

LACEY, H. 1998. Valores e atividade cientifica. São Paulo: Discurso.

LEITE LOPES, J. 1981. O desenvolvimento da ciência e os povos do Terceiro Mundo. Revista Paz e Terra, São Paulo, ano II, n. 8, set.

MARQUES, F. 2008. Avaliação revela alto grau de eficiência em quatro programas da Fapesp. SP Notícias, São Paulo, 25.maio. Disponível em: http://www.saopaulo.sp.gov.br/spnoticias/ lenoticia.php?id=95168. Acesso em: 15.set.2011.

MATUS, C. 1996. Política, planejamento e governo. Brasília: Instituto de Pesquisa Econômica Aplicada.

NSF. 2006. Science and Engineering Indicators 2006. Arlington: National Science Foundation.
Disponível em: http://www.nsf.gov/statistics/ seind06/. Acesso em: 15.set.2011.

PAIM, N. \& NICOLSKY, R. 2006. Inovação e crescimento sustentado. JC E-mail, São Paulo, 8.jun. Disponível em: http://www. jornaldaciencia.org.br/Detalhe.jsp?id=38202. Acesso em: 15.set.2011.

RAPINI, M. S. 2007. Interação universidadeempresa no Brasil: evidências do Diretório dos Grupos de Pesquisa do CNPq. Estudos Econômicos, São Paulo, v. 37, n. 1, p. 211-233, jan.-mar. Disponível em: http://www.scielo.br/ pdf/ee/v37n1/08.pdf. Acesso em: 15.set.2011.

ROTH, A. 2006. Políticas públicas: formulación, implementación y evaluación. Bogotá: Aurora.

SILVA, R. B. 2008. Pólo e Parque de Alta Tecnologia de Campinas: uma análise da política pública. Campinas. Dissertação (Mestrado em Política Científica e Tecnológica). Universidade Estadual de Campinas. Disponível em: http://cutter.unicamp.br/document/ ?code $=000434012$. Acesso em: 15.set.2011.

SOUZA, M. \& GARCIA, R. 1998. O arranjo produtivo de indústrias de alta tecnologia da região de Campinas. Nota técnica n. 27/99. Rio de Janeiro: UFRJ. Disponível em: http:// www.ie.ufrj.br/redesist/P1/texto/NT27.PDF. Acesso em: 15.set.2011.

TERRA, J. C. \& WEISS, J. M. 2002. Rumo d̀ "sociedade do conhecimento": as trajetórias do Brasil e da Coréia do Sul. Artigo apresentado no XXII Simpósio de Gestão da Inovação Tecnológica, realizado em Salvador, de 6 a 9 de novembro. Disponível em: http:// governo.terraforum.com.br/Documents/ libdoc00000021v001Sociedade $\% 20 \mathrm{do} \% 20$ Conhecimento\%20-\%20Brasil\%20x\%20 Corei.pdf. Acesso em: 15.set.2011.

THOMAS, H.; DAVYT, A.; GOMES, E. \& DAGNINO, R. 1997. Racionalidades de la interacción universidad-empresa en América Latina y el Caribe (1955-1995). Educación Superior y Sociedad, Caracas, v. 8, n. 1. Disponível em: http://ess.iesalc.unesco.org.ve/ index.php/ess/article/view/289. Acesso em: 15.set.2011 


\section{OUTRAS FONTES}

FAPESP. 2008. Inovação tecnológica: programas PITE e PIPE. São Paulo: Fundação de Amparo à Pesquisa do Estado de São Paulo. Disponível em: http://watson.fapesp.br . Acesso em: 10.jul.2008.

IBGE. 2000. Pesquisa industrial de inovação tecnológica (Pintec). Brasília: Instituto Brasileiro de Geografia e Estatística.

2003. Pesquisa industrial de inovação tecnológica (Pintec). Brasília: Instituto Brasileiro de Geografia e Estatística.

2005. Pesquisa industrial de inovação tecnológica (Pintec). Brasília: Instituto Brasileiro de Geografia e Estatística.
INOVA UNICAMP. 2006. Relatório de atividades 2006. Campinas: Agência de Inovação da Universidade Estadual de Campinas.

SEADE. 2006. Atlas de competitividade da indústria paulista. São Paulo: Fundação Sistema Estadual de Análise de Dados. Disponível em: http://intranet.seade.gov.br/projetos/fiesp/ . Acesso em: 15.set.2011.

UNICAMP. 2007. Anuário de pesquisa da Unicamp 2007. Campinas: Universidade Estadual de Campinas. Disponível em: http:// www.unicamp.br/anuario/2007/Pesquisa/ index_pesquisa.html. Acesso em: 15.set.2011.

USP. 2007. Anuário de Pesquisa da USP 2007. São Paulo: Universidade de São Paulo. 
POLICY ANALYSIS APPROACH FOR THE STUDY OF PUBLIC POLICY ON THE HIGH TECH INDUSTRIAL PARK OF CAMPINAS

Rogério Bezerra da Silva and Renato Dagnino

This article analyzes public policy on the High Tech Industrial Park of Campinas which, following the guidelines of Brazilian scientific and technological policy, has been elaborated over the course of the last three decades. For these purposes, we use the Policy Analysis Approach. It not only requires comparison of policy goals and the results obtained through their implementation, but also seeks to 
explain obstacles to reaching goals by examination of policies from the first moments of their formulation. That is, analysis of the decision-making process, political projects and cognitive models of the actors involved. The analysis we carry out shows that three decades after the initiation of this particular public policy, only modest results have been achieved. The explanation for this may reside in the fact that it attempted to emulate experiences originating in advanced capitalist countries, on the initiative of members of the national research community.

KEYWORDS: Policy Analysis Approach; public policies; High Tech Industrial Park of Campinas. 


\section{L'ACCENT SUR L'ANALYSE DE POLITIQUES ET LA POLITIQUE PUBLIQUE DU "PÔLE} ET PARC DE HAUTE TECHNOLOGIE DE CAMPINAS"

Rogério Bezerra da Silva et Renato Dagnino

L'article analyse la politique publique du « Pôle et Parc de Haute Technologie de Campinas », qui est produite depuis trente ans, autant qu'une des orientations de la politique scientifique et de la technologie brésilienne. Pour cela, on utilise l'Accent sur l'Analyse de Politiques; ce qui n'exige pas seulement la comparaison entre deux objectifs de la politique et les résultats atteints avec sa mise en oeuvre. Il cherche à expliquer les échecs à la reálisation des objectifs, à partir de la vérification de son moment de formulation. C'est à dire, du processus de décision et des projets politiques, et des modèles cognitifs des acteurs qui lui sont impliqués. L'analyse réalisée montre qu'après trente ans depuis le début de cette Politique Publique, ses résultats se montrent très faibles. L'explication pour cela, peut être le fait qu'elle ait été une émulation d'expériences similaires qui ont eu lieu dans des nombreux pays au capitalisme avancé, par l'initiative des membres de la communauté de recherche nationale.

MOTS-CLÉS: L'Accent sur l'Analyse de Politiques ; les Politiques Publiques ; le Pôle et Parc de Haute Technologie. 